\title{
LA CERÁMICA PREHISPÁNICA TARDÍA DE TARAPACÁ, SUS VALLES INTERIORES Y COSTA DESÉRTICA, NORTE DE CHILE (CA. 900-1.450 D.C.): UNA PROPUESTA TIPOLÓGICA Y CRONOLÓGICA
}

\author{
LATE PREHISPANIC POTTERY OF THE INLAND VALLEYS AND \\ DESERT COAST OF TARAPACÁ, NORTHERN CHILE (CA. A.D. 900-1,450): \\ A TYPOLOGICAL AND CHRONOLOGICAL PROPOSAL
}

\author{
Mauricio Uribe $^{1}$, Lorena Sanhueza ${ }^{1}$ y Francisco Bahamondes ${ }^{1}$
}

\begin{abstract}
Este artículo refiere al material cerámico de poblados arqueológicos de la región de Tarapacá ubicados en las quebradas altas, valles bajos y la costa al este y oeste de la Pampa del Tamarugal. Nuestro objetivo ha sido sistematizar nuestros anteriores estudios y los análisis de otros investigadores acerca de la cerámica de la región para actualizar el conocimiento en torno a la historia cultural y los procesos sociales relacionados con el aún poco conocido complejo Pica Tarapacá del Norte de Chile. Al respecto, proponemos que este complejo cultural se desarrolló durante el período Intermedio Tardío al menos en dos fases, una inicial y otra clásica, las que denominamos fase Tarapacá (ca. 900-1.250 d.C.) y Camiña (ca. 1.250-1.450 d.C.), respectivamente. Se plantea una tradición alfarera local que nació a fines del período Formativo y que luego, en ausencia de influencias estilísticas Tiwanaku, integró elementos nuevos del altiplano meridional, siendo este último el panorama que predominaría en la región a la llegada del Inka. Lo anterior pretende contribuir con mayor evidencia empírica a la discusión acerca de las dinámicas sociales e interacción económica entre las tierras bajas y altas de los Desarrollos Regionales (período Intermedio Tardío) de esta parte de los Andes Centro Sur.
\end{abstract} dio Tardío.

Palabras claves: complejo cultural Pica Tarapacá, tipología y análisis cerámicos, secuencia y fases, período Interme-

In this paper we study the ceramic material from the archaeological villages of the Tarapaca region, located in the high ravines, the low valleys, and the coast to the west and east of Pampa del Tamarugal. Our objective is to do a systematic review of earlier studies by ourselves and by other investigators of domestic pottery in the region, to update knowledge about the culture history and social processes related to the still poorly known Pica Tarapacá cultural complex of northen Chile. We propose that this cultural complex developed during the Late Intermediate Period in at least two phases, initial and classic, that we have named Tarapacá Phase (ca. A.D. 900-1,250) and Camiña Phase (ca. A.D. 1,250-1,450), respectively. We propose a local pottery tradition that began toward the end of the Formative Period and then, in the absence of Tiwanaku stylistic influences, incorporated new elements from the southern altiplano. This was the panorama that dominated the region when the Inka arrived. This work is intended to contribute with greater empirical evidence to the discussion about social dynamics and economic interaction between lowlands and highlands of this part of the South Central Andes during the Regional Developments of the Late Intermediate Period. Period.

Key words: Pica Tarapacá cultural complex, ceramic typology and analysis, sequences and phases, Late Intermediate

Este artículo está referido al material cerámico recuperado en recolecciones superficiales de los sitios arqueológicos Caserones 1, Camiña 1, Chusmisa, Nama 1, Jamajuga o Cerro Gentilar y Tarapacá Viejo o Tr 49 (Niemeyer 1961; L. Núñez 1965a, 1984; P. Núñez 1984), pertenecientes respectivamente a las quebradas de Tarapacá, Camiña y Mamiña en la subárea de Valles
Occidentales del Norte Grande de Chile (Figura 1). A ellos se suman los materiales de los sitios Pisagua B y N de la costa aledaña (Adán y Urbina 2004; Moragas 2004), todos adscritos o vinculados al identificado pero aún poco conocido complejo cultural Pica o Pica Tarapacá del período Intermedio Tardío (Núñez 1965b; Schiappacasse et al. 1989).

1 Departamento de Antropología, Facultad de Ciencias Sociales, Universidad de Chile. Ignacio Carrera Pinto 1045, Ñuñoa, Santiago.mur@uchile.cl; loresan@uchile.cl; fjabm@yahoo.com 


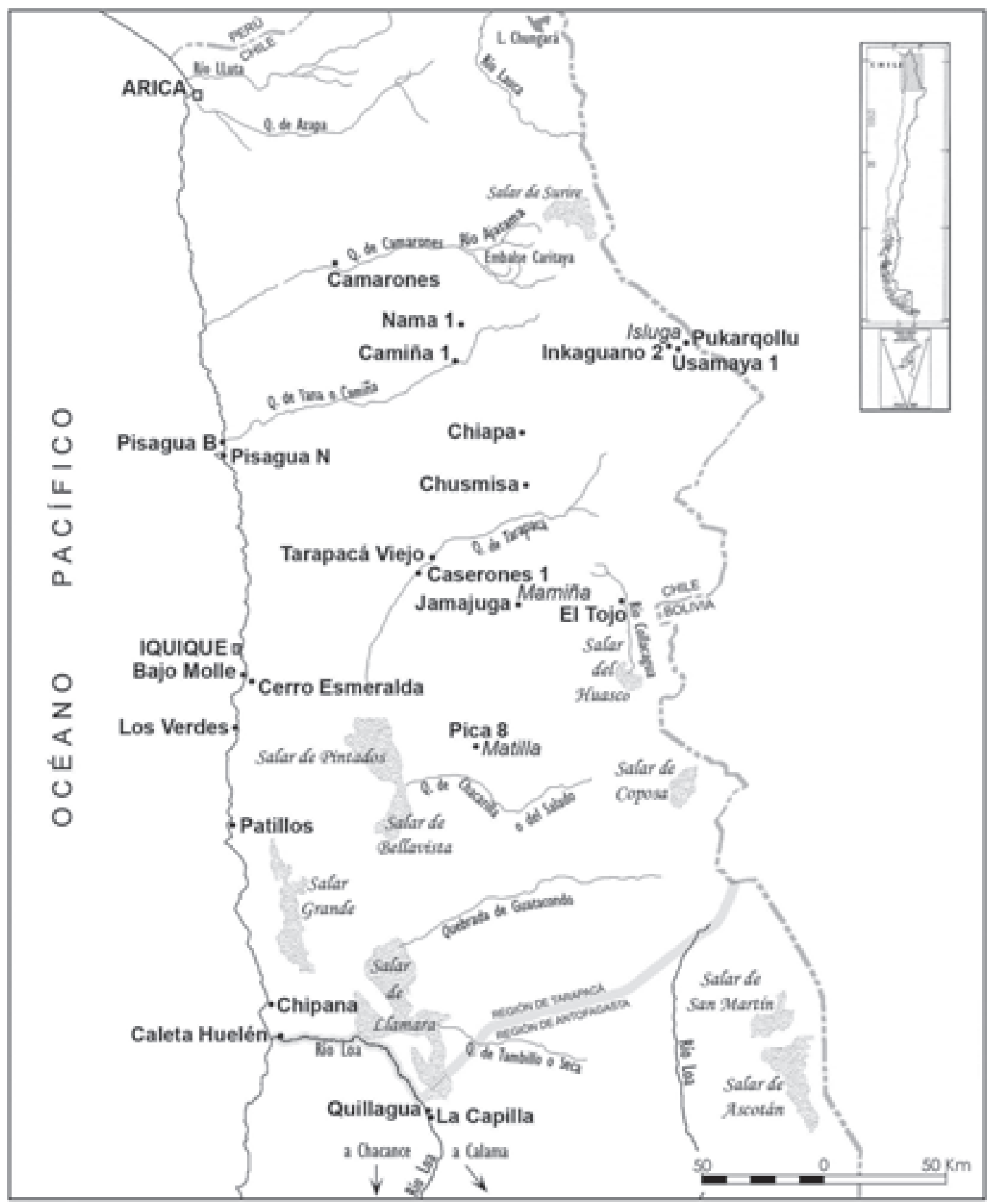

Figura 1. Mapa de la región y principales sitios del complejo cultural Pica Tarapacá y localidades mencionadas en el texto. Map of the region, the principal sites of the Pica Tarapacá cultural complex, and other places mentioned in the text.

En este sentido, ya que se trata de un territorio donde la investigación arqueológica, comparada con las regiones de Arica y Atacama, ha sido discontinua y/o irregular en el tiempo, sobre todo durante los períodos prehispánicos tardíos (Moragas 1995;
Núñez 1965b; Schiappacasse et al. 1989), el interés se centra en sistematizar nuestros propios estudios y otros análisis cerámicos de la región para actualizar la discusión en torno a la historia cultural y los procesos relacionados con el denominado 
complejo Pica Tarapacá desde la alfarería. Lo anterior forma parte de una investigación más amplia, la que se propone analizar diferentes materialidades del Intermedio Tardío para comprender arqueológicamente los sistemas sociales que desarrollaron las poblaciones a partir de un caso concreto como Pica Tarapacá (Uribe 2006a; Uribe y Adán 2005). Todo esto, en particular, aspira a contribuir con una comprensión arqueológica y crítica de las sociedades prehispánicas tardías del Norte Grande de Chile en el marco de los Andes Centro Sur (ca. 1.000-1.500 d.C.).

Además, como la investigación de la región se ha basado principalmente en una arqueología funeraria (Núñez 1965a, 1979; Zlatar 1984), nuestra idea es avanzar en su estudio a través de la información brindada por la cerámica, esencialmente fragmentaria, de contextos domésticos pertenecientes a los sitios habitacionales que presentamos en este trabajo. Para ello hemos realizado una evaluación de los antecedentes cerámicos de la región desde el período Formativo en adelante, integrando la información del resto de las quebradas y oasis interiores, de la costa de Iquique hasta el río Loa y la procedente del Altiplano Meridional colindante, así como la información pertinente del resto de los Valles Occidentales y la subárea Circumpuneña. Gracias a ello, proponemos una tipología con la que clasificamos el material cerámico y evaluamos estadísticamente el comportamiento de los fragmentos en relación con su distribución dentro y entre los sitios estudiados, precisando la adscripción cultural y la secuencia relativa respecto a la historia cultural de Pica Tarapacá. Por lo mismo, también incluimos una discusión cronológica respecto a los fechados absolutos de la región y los comparamos con nuestras propias dataciones, haciendo referencia al comportamiento estratigráfico de la cerámica de acuerdo a las excavaciones que realizamos en Caserones, Camiña y otros sitios para fortalecer nuestras propuestas.

\section{La Cerámica Arqueológica de Tarapacá}

Al centrarnos en la problemática arqueológica del territorio comúnmente denominado Tarapacá, comprendido entre la quebrada de Camiña o Tana y el río Loa, resulta evidente respecto a Arica y Atacama la escasez de investigaciones sistemáticas sobre cerámica (Uribe 2004), a pesar de involucrar un amplio y rico espacio comprendido por la Pampa del Tamarugal, sus quebradas endorreicas, la costa arreica y el altiplano asociado. Por lo tanto, para una comprensión más cabal del desarrollo de esta materialidad y su estudio, iniciamos nuestro trabajo con una revisión de los antecedentes cerámicos de la región durante los períodos agroalfareros, que sirve de base para clasificar y analizar los restos fragmentarios de los sitios adscritos al complejo Pica Tarapacá.

\section{Antecedentes de la Cerámica en el Período Formativo Tardío}

Siguiendo las primeras apreciaciones de Uhle, Latcham (1938) planteaba que la alfarería hacía su aparición en la costa de la "región atacameña" antes y durante la época Tiwanaku, uno de cuyos centros era Pisagua donde sería más bien "primitiva" (Latcham 1938:223). Coincidente con lo anterior, Bird (1943) también distingue cerámica temprana caracterizada por los fragmentos del conchal Brown Refuse, en especial no decorada y de bordes engrosados. La misma alfarería continuaría en el conchal más tardío llamado Black Refuse, pero con la notable falta de los bordes tempranos. Así, el autor considera a esta cerámica como antecesora de las fases I y II de Arica, pudiendo también ser contemporánea a las épocas "Tiwanaku" y "Atacameña" de Uhle y Latcham (Schaedel y Munizaga 1957:73). En consecuencia, desde los albores de la arqueología chilena queda constancia de la existencia de alfarería temprana en la Región de Tarapacá, particularmente concentrada en la costa. Desde entonces, varios autores plantean que una de las primeras tradiciones cerámicas que llegó al norte y costa chilena fue la café alisada proveniente de alguna población relacionada con la cultura Wankarani de Bolivia o desarrollos emparentados de valles bajos, cuya tecnología fue adoptada por las poblaciones arcaicas marítimas, ya sea por contacto directo o indirecto con comunidades altiplánicas (Aufderheide et al. 1994; L. Núñez 1967-68, 1970, 1971, 1982, 1984; Núñez y Moragas 1983; Rivera 1988$89,2002)$. Todo esto ha generado una gran discusión en torno al período Formativo de los Valles Occidentales y los denominados complejos culturales Faldas del Morro y Alto Ramírez (Muñoz 1989, 2004; Núñez 1970; True 1980).

Luego de estos estudios pioneros y más allá de la discusión sobre su origen local o foráneo, 
aunque sin ver mayores vinculaciones con el altiplano, actualmente reconocemos dos expresiones cerámicas para el Formativo de Tarapacá, destacando una alfarería inicial y otra más tardía (Ayala 2001; Uribe y Ayala 2004). Gracias a nuestros trabajos en la región, hemos registrado alfarería con todas las características que se mencionan para una industria inicial de vasijas con bordes en coma, la cual hemos confirmado por termoluminiscencia como la más temprana en Quillagua con fechas de 730 a.C., de amplia distribución areal y que denominados tipo Loa Café Alisado al identificarla por primera vez en la cuenca homónima, aunque también se adscribe a Alto Ramírez (Agüero et al. 2001; Rivera 2002; Sinclaire et al. 1998; Uribe y Ayala 2004). La segunda, que realmente nos interesa por mostrar una continuidad hasta momentos más tardíos, es una industria compuesta por distintos tipos alisados y pulidos, concentrados en las quebradas y valles del interior de la Pampa del Tamarugal (Mavrakis 1985; True 1980; Uribe y Ayala 2004).

Los primeros los agrupamos dentro del tipo Quillagua Tarapacá Café Amarillento, principalmente identificado en los cementerios de Tarapacá 40 y también en Pica (Moragas comunicación personal 2003), así como en sitios habitacionales y funerarios de Quillagua donde alcanza el 23\% de frecuencia, mientras que en la costa es sumamente escaso. Se caracteriza por pastas arenosas muy diversas debido a una producción expeditiva, en especial de miniaturas que muchas veces ni siquiera fueron cocidas, donde se reconocen vasijas restringidas simples y no restringidas, en su mayoría pequeños cuencos, pocillos, ollas o vasos (Figura 2$)^{1}$. Las superficies fueron dejadas sin mayor tratamiento, mostrando el raspado o espatulado de instrumentos, huellas de los dedos del artesano, así como improntas de cestería. Su uso fue doméstico y ceremonial, destacando como recipientes de ofrendas, asociados a alimentos cultivados. Luego distinguimos el tipo Quillagua Rojo Pulido (Figura 2); es escaso pero recurrente $(0,4 \%$ en Quillagua), presenta pastas de aspecto arenoso como las de Tarapacá, comprende formas no restringidas y restringidas a modo de vasos y botellas que pueden aparecer con mamelones en el borde o cuello. Esta situación es idéntica a la observada en Caserones, si bien las tonalidades varían de rojo a negro (Mavrakis 1985; True 1980), distinguiéndose aquí un grupo propio que adscri- bimos al Caserones Negro Pulido de estos autores (Figura 2). Debido a su mayoritaria presencia desde Tarapacá hasta Quillagua se propone un origen local para esta alfarería alisada y pulida, de carácter tanto doméstico como ceremonial, cuyo apogeo se remontaría a momentos del Formativo Tardío de acuerdo a los fechados por termoluminiscencia que hemos obtenido para ella en Quillagua entre el 660 y 665 d.C. (Agüero et al. 2001), pudiendo incluso retraerse hasta el 200 d.C. y mantenerse hasta el primer milenio de nuestra era (Gallardo et al. 1991; Oakland 2000; True 1980), constituyendo la base de la alfarería del Intermedio Tardío.

\section{La Cerámica del Período Intermedio Tardío}

Posterior al Formativo, se ha integrado a las comunidades de los valles y quebradas al oriente de la Pampa del Tamarugal, dentro del complejo cultural Pica Tarapacá, abarcando la costa desértica y la sierra desde Camiña hasta el río Loa (Schiappacasse et al. 1989). Este complejo es definido generalmente por una tradición cerámica monocroma de vasijas restringidas, alisadas o estriadas y sin asas (Núñez 1965b) que nosotros definimos como componente Pica Tarapacá ${ }^{2}$, cuyas características nos recuerdan la alfarería formativa, permitiéndonos hipotetizar una línea directa de evolución desde ella. No obstante, para el mismo período, también reconocemos la introducción de cerámica alisada y pulida, revestida roja y/o decorada en negro que comúnmente se adscribe al altiplano (Schiappacasse et al. 1989) y que denominamos componente Altiplano Tarapacá. Por lo tanto, nos abocamos a una detallada descripción de ambos componentes cerámicos.

\section{El componente Pica Tarapacá}

El complejo Pica Tarapacá fue inicialmente caracterizado por las manifestaciones cerámicas de Pica (Núñez 1965b), equivalente a lo que Dauelsberg (1972-1973) llamó tipo Charcollo para Arica y Camarones, de color café con baño rojo sobre superficie brochada, estriada o rasmillada, cuyas formas predominantes serían de cuerpos globulares con cuello corto, estrecho, sin asas, con mamelones y base cónica, junto con modelados zoomorfos y antropomorfos de tipo Chiza. Al respecto, se propone que gran parte de la cerámica 

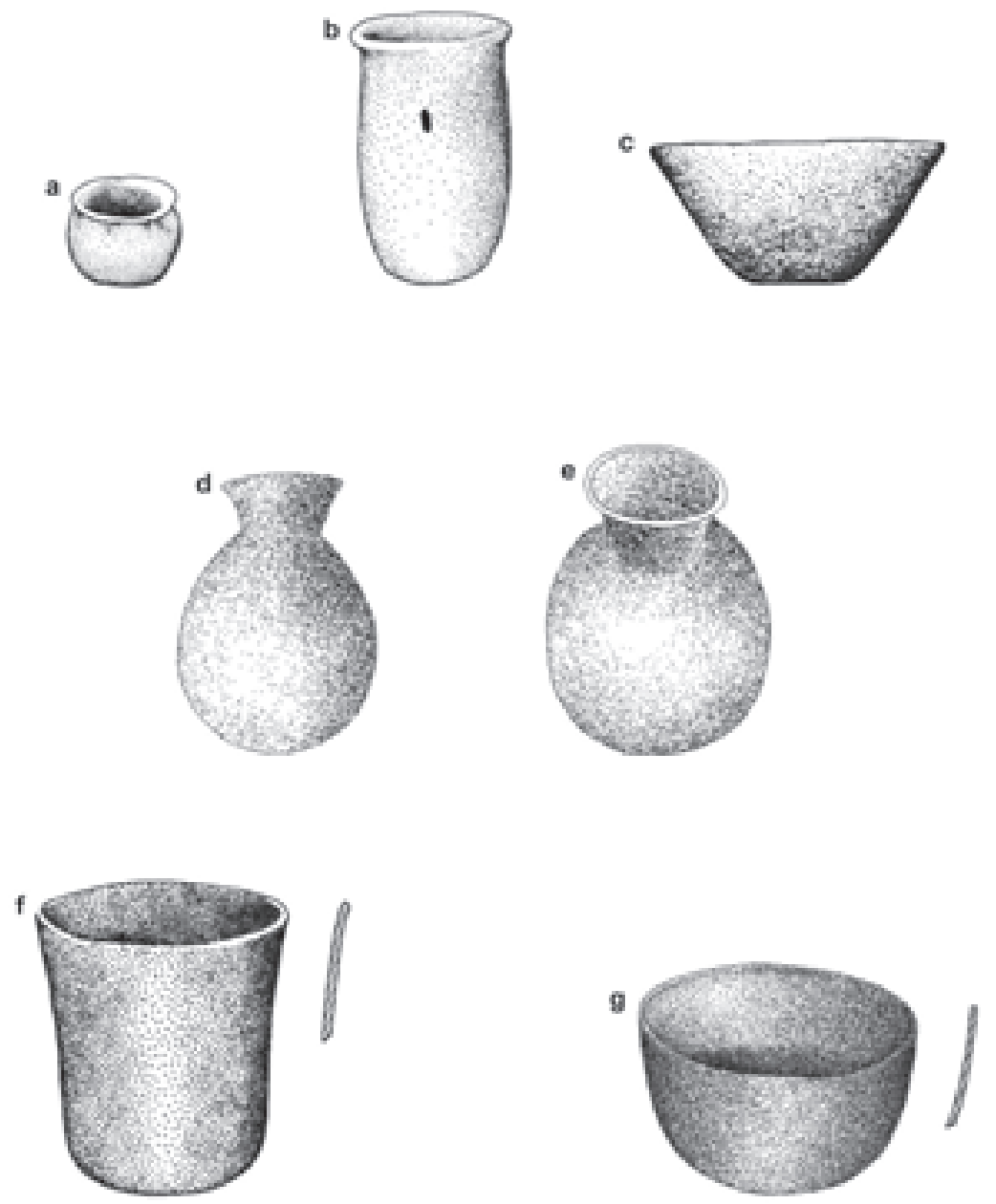

Figura 2. Componente cerámico Formativo Tardío de Tarapacá: (a-c) tipo Quillagua Tarapacá Café Amarillento QTC (pocillo, vaso y tazón), sitio Tarapacá 40a-b (Uribe y Ayala 2004); (d-e) tipo Quillagua Rojo Pulido QRP (botellas), sitio Pica-Quisma (Moragas comunicación personal 2003); (f-g) tipo Caserones Negro Pulido CNP (vaso y escudilla), sitio Caserones 1 (Mavrakis 1985; True 1980). Escala $=1 \mathrm{~cm}$.

Late Formative ceramic component of Tarapacá: (a-c) Quillagua Tarapacá Yellow Brown QTC type (bowls and vase), Tarapacá 40a-b site (Uribe and Ayala 2004); (d-e) Quillagua Polished Red QRP type (bottles), Pica-Quisma site (Moragas personal communication 2003); ( $f$-g) Caserones Polished Black CNP type (vase and bowl), Caserones 1 site (Mavrakis 1985; True 1980). Scale $=1 \mathrm{~cm}$.

monocroma de la costa procedería en tiempos tardíos de valles similares a Pica. Para el cementerio Molle Bajo de Iquique se describe el tipo Pica como una cerámica con forma de pucos y pequeñas botellas, además de cántaros de base cónica y sin asas, todos con superficie rojiza y brochada (Moragas 1995). En menor cantidad aparecen ejemplares antropomorfos como ornitomorfos ad- judicados a Chiza y jarros de Arica con decoración policroma San Miguel, aparte de ejemplares Gentilar descubiertos en la misma ciudad. La generalidad de la cerámica tendría una apariencia bastante burda y no sería muy abundante, si bien aparece una vasija Chiza asociada a un personaje de alta jerarquía, indicando la existencia de piezas importantes. Las fechas de radiocarbono no cali- 
bradas del sitio son $1.247,1.252,1.253$ y 1.258 d.C. (Moragas 1995). Al sur de Iquique, en tanto, se han recuperado contextos semejantes en los cementerios de El Patillo o Patillos, pues entre la escasa cerámica destacan las piezas monocromas (Schaedel y Munizaga 1957); mientras que en menor cantidad aparecen tiestos Chiza y San Miguel (Moragas 1995). Esto sería sumamente idéntico a lo que ocurre en Los Verdes (Sanhueza 1985), sitio funerario y habitacional que exhibe los típicos tiestos de Pica y los decorados de Arica, contando con otro fechado no calibrado de 1.100 d.C. (Moragas 1995). Y, acercándose al río Loa, se encuentran los cementerios de Chipana donde se registraron vasijas Chiza y el material monocromo estriado (Moragas 1995), donde es posible distinguir la combinación con piezas circumpuneñas correspondientes a las escudillas Aiquina y Dupont de Atacama. Lo anterior resulta evidente en la desembocadura del Loa (Núñez 1971; Spahni 1967), donde existe gran concentración de sitios funerarios y habitacionales, en los cuales se ha registrado cerámica atacameña del Intermedio Tardío (Moragas 1995), asociada a alfarería Charcollo, Chiza y tampoco faltan los ejemplares policromos San Miguel y Gentilar de Arica (Moragas 1995). Lo mismo se repetiría hacia el interior, sugerido por el sitio habitacional $\mathrm{La} \mathrm{Ca}$ pilla en Quillagua que cuenta con una fecha de radiocarbono no calibrada de 1.240 d.C. (Cervellino y Téllez 1980). De hecho, acercándose a los oasis loínos los tipos Pica han sido fechados por termoluminiscencia entre el $745,1.055$ y 1.110 d.C. en los cementerios de Chacance y Oriente de Quillagua (Agüero 1998; Agüero et al. 1997, 1999). Mientras que en el límite septentrional del complejo existen fechados de 950 d.C. para cerámica similar en el poblado de Conanoxa (Schiappacasse et al. 1991), hasta dataciones más tardías de 1.420 y 1.450 d.C. provenientes de una aldea al norte de la desembocadura de Camarones (Schiappacasse et al. 1991). Ingresando a los valles tarapaqueños, junto con Pica 8 en Matilla (Zlatar 1984), la misma alfarería se extendería a otros cementerios entre Pica y Quisma donde se han registrado jarros monocromos y tiestos modelados (Moragas 1995). Las tempranas excavaciones en los cementerios de Pica, especialmente en Santa Rosita (Niemeyer 1959, 1962a), reconocen alfarería doméstica o utilitaria, correspondientes a pucos, botellas y cántaros periformes, junto a pie- zas dobles tipo Chiza (Niemeyer 1959, 1962a). Hasta esos momentos, sin embargo, faltaban las piezas decoradas aunque en estudios posteriores del mismo cementerio aparecen algunos ejemplares de Arica tanto San Miguel como Pocoma y un posible espécimen altiplánico (Niemeyer 1962a). Toda esta cerámica de Pica y Quisma, por otro lado, aparecería fechada en 1.020 d.C. de acuerdo a las escasas dataciones de radiocarbono no calibradas para Pica 8 (Núñez 1965b).

En la actualidad, hemos propuesto que los tipos Charcollo y Chiza de Tarapacá (Ayala y Uribe 1996; Uribe 1999b) son estructural y tecnológicamente distintos a los que aparecen en Arica pues no muestran las mismas características tecnológicas y estilísticas, no tienen la representación que alcanzan en Pica 8, ni presentan idénticas asociaciones culturales aunque muchas veces han sido llamados de la misma manera (Dauelsberg 1972-73; Zlatar 1984). De acuerdo a lo anterior, redefinimos el tipo Pica Charcollo (Figura 3) por pastas graníticas de aspecto arenoso a granuloso, densa en inclusiones blancas, cuarzo y escasa mica, de cocción oxidante completa y color café, con las que se produjeron por ahuecado y enrollamiento formas mayoritariamente restringidas. En todos los casos las superficies fueron alisadas, pero el exterior del cuerpo presenta un tratamiento caracterizado por gran cantidad de estrías hechas con un instrumento duro y distribuidas heterogéneamente por todo el cuerpo de la vasija, donde es frecuente observar la aplicación dispareja y descuidada de un engobe o revestimiento rojo. Se trataría de botellas y cántaros de cuerpos esféricos y ovoides, con cuellos evertidos, relativamente cortos, algunos muy estrechos y otros anchos, generalmente con pequeños mamelones subcónicos emplazados en lados opuestos del cuello; las bases son convexas y apuntadas respectivamente, estas últimas con un engrosamiento a modo de torus con alisado muy burdo. Tampoco faltarían vasijas no restringidas de cuerpo semiesférico a modo de escudillas o pucos, así como vasijas restringidas de cuerpo simétrico y asimétrico, algunas con un asa en el cuello (comúnmente llamadas jarros zapatos), usadas como ollas por el tizne que casi siempre aparece en sus superficies. Estas ollas, las separamos como una variante Pica Gris Alisado donde también se encuentran vasijas de cuerpo ovoide con mamelones y sin asas (Figura 3). 


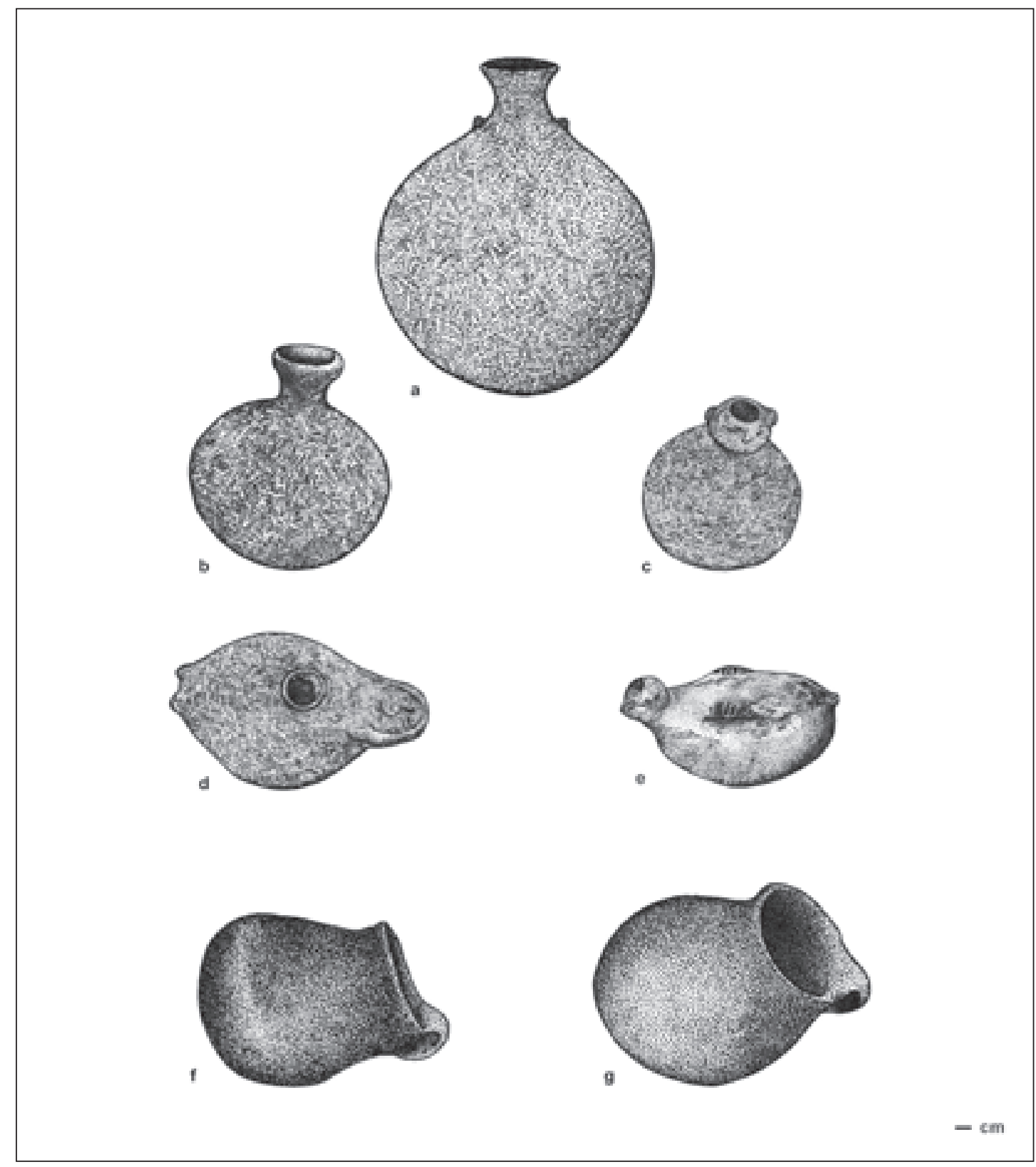

Figura 3. Componente cerámico Pica Tarapacá: (a-b) tipo Pica Charcollo PCH (botellas con y sin mamelones), sitio Pica 8 (Agüero et al. 1997, 1999; Zlatar 1984); (c-e) tipo Pica Chiza PCZ (botellas antropomorfas y zoomorfa), sitio Pica 8 (Agüero et al. 1997, 1999; Zlatar 1984); (f-g) tipo Pica Gris Alisado PGA (ollas asimétricas), sitio Pica 8 (Agüero et al. 1997, 1999; Zlatar 1984). Escala $=1 \mathrm{~cm}$.

Pica Tarapacá ceramic component: $a$-b) Pica Charcollo PCH type (bottles with and without protuberances), Pica 8 site (Agüero et al. 1997, 1999; Zlatar 1984); (c-d) Pica Chiza PCZ type (anthropomorphic and zoomorphic bottles), Pica 8 site (Agüero et al. 1997, 1999; Zlatar 1984); (f-g) Pica Smoothed Grey PGA type (asyimmetrical pots), Pica 8 site (Zlatar 1984; Agüero et al. 1997, 1999). Scale $=1 \mathrm{~cm}$.

Por su parte, distinguimos un tipo Pica Chiza (Figura 3) con pastas que, como también fue observado por Núñez (1965b), implicarían variaciones del Charcollo donde predominarían aquellas de aspecto arenoso más fino (Dauelsberg 19721973). Del mismo modo, se trataría de piezas restringidas correspondientes en su mayoría a botellas, pero también aparecen algunos jarros. Sin 
embargo, lo que particulariza a esta alfarería es la presencia de modelado tridimensional que involucra a casi toda la vasija. De esta manera, se observan botellas y jarros modelados de cara antropomorfa en el cuello, así como botellas asimétricas de cuerpo alargado y modelado de aspecto femenino. A las anteriores, se suman botellas asimétricas con modelados zoomorfos que combinan elementos de las dos formas previas, pero que representarían aves simples, dobles y abstractas, así como camélidos. Por lo general, se aprecia una superficie exterior alisada con manchas oscuras en algunos sectores, en otros estrías de pulimento aplicadas de manera dispareja, e incluso revestimiento rojo muy tenue e irregular como en el Pica Charcollo. El único fechado por termoluminiscencia conocido corresponde a $1.230 \pm 40$ d.C. (UCTL 107) para una muestra del asentamiento Manuel Rodríguez de Camarones (Schiappacasse et al. 1991).
De acuerdo a las dataciones obtenidas (Tabla 1), ambas expresiones cerámicas tendrían su auge entre el 1.020 y 1.258 d.C., aunque el tipo Pica Charcollo aparecería hacia el $750 \pm 130$ d.C. (UCTL 815) y se extendería hasta el $1.450 \pm 50$ d.C. (UCTL 98) de acuerdo a las fechas del curso bajo del Loa, Pisagua y Camarones, traslapándose con los momentos tardíos del Formativo y topando con el Inka. Por lo tanto, esto sugiere una continuidad tecnológica y cultural coincidente con las semejanzas entre los tipos de ambos períodos, configurando una ancestral tradición local de alfarería monocroma y estriada (Uribe y Ayala 2004). Tal situación es bastante coincidente con el planteamiento de Bird (1943) para Pisagua durante la fase Pichalo IV, donde la misma cerámica temprana no decorada y sin engobe del Brown Refuse continuaría en el Black Refuse, siendo notable la falta de los bordes engrosados tempranos o en coma. Y donde, siguiendo a Uhle (1919) y Latcham (1938),

Tabla 1. Cuadro resumen de fechados por termoluminiscencia para los tipos Pica Charcollo y Pica Chiza (a), y las dataciones de radiocarbono asociadas a la cerámica tardía de Tarapacá (b). Summary table of the thermoluminescence dates for the Pica Charcollo and Pica Chiza types (a), and the radiocarbon dates associated with the late pottery of Tarapacá (b).

\begin{tabular}{|c|c|c|c|c|c|}
\hline Muestra & Sitio & $\begin{array}{l}\text { Fechados de Termoluminiscencia } \\
\text { Cerámica }\end{array}$ & Fecha a.p. & Fecha d.C. & Fuente \\
\hline UCTL 815 & Chacance 1 & $\mathrm{PCH}$ & $1.250+/-130$ & 745 & Agüero et al. 1997, 1999 \\
\hline UCTL 100 & Conanoxa Este 1 & $\mathrm{PCH}$ & $1.035+/-90$ & 950 & Schiappacasse et al. 1991 \\
\hline UCTL 101 & Conanoxa Este 2 & $\mathrm{PCH}$ & $1.040+/-100$ & 950 & Schiappacasse et al. 1991 \\
\hline UCTL 735 & Quillagua 1 & $\mathrm{PCH}$ & Sin dato & 1.055 & Agüero 1998 \\
\hline UCTL 736 & Quillagua 1 & $\mathrm{PCH}$ & Sin dato & 1.110 & Agüero 1998 \\
\hline UCTL 107 & Manuel Rodríguez & PCZ & $760+1-40$ & 1.230 & Schiappacasse et al. 1991 \\
\hline UCTL 1636 & Pisagua N & $\mathrm{PCH}$ & $645+/-50$ & 1.355 & Fondecyt 1030923 \\
\hline UCTL 1633 & Pisagua B & PCZ & $605+/-60$ & 1.395 & Fondecyt 1030923 \\
\hline UCTL 99 & Camarones Norte & $\mathrm{PCH}$ & $570+/-30$ & 1.420 & Schiappacasse et al. 1991 \\
\hline UCTL 1632 & Pisagua B & $\mathrm{PCH}$ & $555+/-40$ & 1.445 & Fondecyt 1030923 \\
\hline UCTL 98 & Camarones Norte & $\mathrm{PCH}$ & $540+1-50$ & 1.450 & Schiappacasse et al. 1991 \\
\hline Muestra & Sitio & $\begin{array}{c}\text { Fechados de Radiocarbono } \\
\text { Recinto-Capa }\end{array}$ & Fecha a.p. & Fecha Cal. d.C. & Fuente \\
\hline BETA 220917 & Caserones 1 & R. 7-C. 3 & $1.080+/-40$ & $890-1.020$ & Fondecyt 1030923 \\
\hline BETA 220922 & Pica 8 & S. D-T. $11 *$ & $1.050+/-40$ & $900-1.030$ & Fondecyt 1030923 \\
\hline BETA 210442 & Camiña 1 & R. 296-C. $2 \mathrm{C}$ & $920+/-40$ & $1.020-1.210$ & Fondecyt 1030923 \\
\hline BETA 201435 & Pisagua N & R. 1-C. 3A & $880+/-40$ & $1.030-1.250$ & Fondecyt 1030923 \\
\hline BETA 220921 & Jamajuga & R. 5A-C. 1B & $800+/-50$ & $1.160-1.290$ & Fondecyt 1030923 \\
\hline BETA 210437 & Nama 1 & R. 67-C. 4 & $770+/-70$ & $1.160-1.310,1.370-1.380$ & Fondecyt 1030923 \\
\hline BETA 210441 & Camiña 1 & R. 139-C. 3-4 & $710+/-70$ & $1.200-1.400$ & Fondecyt 1030923 \\
\hline BETA 220920 & Chusmisa & R. 89-R. $1^{* *}$ & $570+/-50$ & $1.300-1.430$ & Fondecyt 1030923 \\
\hline
\end{tabular}

\footnotetext{
* Sector-Tumba.

***Rasgo.
} 
haría su presencia alfarería tardía de Arica como San Miguel y Pocoma Gentilar, además de ejemplares tardíos del Loa y San Pedro identificados por nosotros en las cercanías (Agüero et al. 1997, 1999).

\section{El componente Altiplano Tarapacá}

En las quebradas altas al pie del altiplano, en poblados de la sierra como el Pucara de Mocha también se reconoce cerámica monocroma con estrías y baño rojo aplicado en forma dispareja, sobre grandes cántaros de base cónica, cuello corto y estrecho, sin asas y con desgrasante grueso de cuarzo (Moragas 1991). Según esto, la mayoría de la alfarería se adscribe al complejo Pica Tarapacá, alcanzando un 35,6\% de representación (Moragas 1991; Núñez 1968), al cual se suman ejemplares Chiza del cementerio aledaño. De aquí se obtuvo un fechado de radiocarbono no calibrado del 1.230 d.C. en plena asociación con la cerámica estriada (Moragas 1991), la única que se identificó en estratigrafía confirmando la adscripción del poblado a dicho complejo. Una situación muy semejante se repetiría en Pachica y la fase temprana de Tarapacá Viejo o Tr 49 (L. Núñez 1979; P. Núñez 1983, 1984). Pero, paralelamente, en Mocha también se identifica una alta frecuencia de alfarería adscrita a un estilo altiplánico $(23,4 \%)$, en particular se trata de cerámica roja con decoración en negro correspondiente a líneas rectas y paralelas, finas y gruesas, círculos, espirales y reticulados, de manera análoga al tipo Chilpe (Dauelsberg 1972-1973), realizados en pucos y jarros. Además, aparece un pequeño porcentaje de alfarería policroma San Miguel (3,6\%), aparte de otra cerámica no revestida de color natural, con pintura anaranjada irregular y ejemplares bicolores (Moragas 1991).

Mucho de ese material ha sido adjudicado al desarrollo altiplánico de la localidad de Isluga (Moragas 1995), al oriente de la sierra tarapaqueña. Respecto a esa alfarería, en el altiplano se ha diferenciado cerámica local y foránea, así como no decorada y decorada (Sanhueza y Olmos 1981), especialmente a través de lo observado en el sitio funerario de Usamaya 1. Entre los tipos decorados, el Isluga Negro sobre Rojo destaca por su mayor frecuencia (Sanhueza y Olmos 1981), donde se distinguen pucos, ollas grandes y pequeñas, botellas y botellones elipsoides, ovoides y esféri- cos, hechos con rollos. Sus pastas contienen antiplásticos de cuarzo, feldespato, biotita y arena en general, de granulometría fina a mediana, distribuidos de manera uniforme y textura compacta a semicompacta, a veces laminar; cocidas en ambiente oxidante y de color café claro a naranja oscuro. Las superficies fueron revestidas rojas, a veces pulidas y luego pintadas en negro por el exterior y/o interior; destacando líneas delgadas, anchas, onduladas o quebradas en el borde, cuerpo y/o asas de vasijas restringidas; volutas, líneas onduladas, semicírculos, puntas y líneas rectas u onduladas entre paralelas en el borde de los pucos (Sanhueza y Olmos 1981). Una variante del anterior sería el tipo Isluga Rojo sobre Naranja; mientras que como tipos foráneos se distinguen otros exponentes altiplánicos correspondientes a Taltape (Dauelsberg 1984), además de los tipos policromos de Arica, incaicos, coloniales y etnográficos. Por su parte, la cerámica no decorada se compondría de los tipos Isluga Engobado Amarillo, Isluga Alisado Naranja e Isluga Estriado ${ }^{3}$ (Sanhueza y Olmos 1981), a los cuales se sumarían las variantes engobadas incaicas, los pulidos coloniales y grises actuales. Sólo se menciona un fechado de radiocarbono no calibrado de 1.635 d.C. para cerámica negro sobre rojo (Ponce 1961), asociada al Inka y materiales coloniales para un sitio de Kanasa en tierras Carangas de Bolivia, adyacentes a Isluga (Sanhueza y Olmos 1981:198).

Según nuestras propias observaciones, la misma situación se presentaría en el sitio habitacional de Pukarqollu o Pucara de Isluga (Sanhueza 1981). De igual modo que en el poblado de Siñahuache o Pucara de Chiapa y en sitios de tiempos incaicos como el tambo de Inkaguano 2 (Reinhard y Sanhueza 1982), e incluso más al sur en El Tojo de Collacagua, al norte del salar de Huasco (Niemeyer 1962b). Aquí se describe cerámica de color pardo, rojizo o marrón, con pasta arenosa de grano fino, a veces con "hojuelas de mica" (Niemeyer 1962b:137), entre las que destacarían ollas, pucos y escudillas. Asimismo, aparece alfarería decorada en negro sobre rojo, con algunos ejemplares ya vistos en el cementerio Santa Rosita de Pica (Niemeyer 1962b).

No deja de ser interesante la información que actualmente se posee sobre la alfarería prehispánica tardía del territorio Carangas (Michel 2000). Aunque sin ninguna evaluación cuantitativa ni fechados absolutos, las vasijas más representativas 
serían los cuencos, platos hondos y/o tazones, además de jarros y jarrones, confeccionados con arcilla de arena fina, cocida en ambiente oxidante. Sus superficies fueron revestidas y pulidas hasta alcanzar el bruñido, sobre el cual se realizó una decoración pintada en negro. Al respecto, las figuras son geométricas y se encuentran cerca del labio, adentro y/o afuera, destacando espirales, líneas onduladas, asteriscos, medios círculos rellenos con onduladas, círculos superpuestos y tramas de enrejados, muchos de los cuales se repiten en el fondo de las piezas. También aparecen figuras zoomorfas gruesas y toscas con aspecto de camélidos. En Chile contamos con una fecha de termoluminiscencia para un fragmento con esta clase de figuras pero que ha sido asignado a cerámica Saxamar o Inka Pacajes de la Hacienda de Camarones, correspondiente a 1.320 d.C. (Schiappacasse et al. 1991). Sin embargo, esto nos parece más coherente con una expresión temprana y preincaica, equivalente al tipo $\mathrm{Pa}$ cajes y compartida con la alfarería de Carangas e Isluga del Intermedio Tardío (Albarracín-Jordán 1996; Pärssinen y Siiriäinen 1997). De hecho, en Pacajes, al norte de nuestro territorio, la principal ocupación del sitio Tiquischullpa que concentra una gran cantidad de esta cerámica en sus estratos medios y bajos, especialmente con figuras de camélidos, presenta fechados calibrados de radiocarbono entre 1.239 y 1.414 d.C. (Pärssinen y Siiriäinen 1997). Del mismo modo, al oriente de Isluga, para la zona intersalar entre Coipasa y Uyuni existen fechas calibradas de 1.270 y 1.425 d.C., donde predomina el tipo Taltape Quillacas junto con distintas variedades decoradas en negro sobre rojo (Lecoq 1999).

De este modo, desplazándose hacia la sierra y el altiplano desde los valles u oasis al oriente de la Pampa del Tamarugal, así como alejándonos de la costa desértica, es posible apreciar una concentración de alfarería decorada bicolor negro sobre rojo (Figura 4), tradicionalmente conocida a través de las escudillas llamadas Chilpe pero también por el tipo Isluga con sus formas principalmente restringidas (Sanhueza y Olmos 1981; Schiappacasse et al. 1989; 1991). Esta cerámica tendría un claro carácter altiplánico vinculado con expresiones análogas, aunque no idénticas del todo, llamadas Konko Kollau, Pacajes Temprano, Taltape Quillacas y Mallku Hedionda (Albarracín-Jordán 1996; Aldunate y Castro 1981; Dauelsberg 1984; Lecoq 1991, 1999; Lecoq y Céspedes 1997; Rydén 1947), que comparten el espacio de quebradas altas y valles bajos con las clásicas expresiones cerámicas monocromas y estriadas tarapaqueñas, aparte de las de Arica y Atacama. Para Chilpe, conocemos un fechado por termoluminiscencia de 1.230 d.C. procedente de Saibapugro en la sierra de Camarones (Schiappacasse et al. 1991), mientras que para su pariente Taltape contamos con una fecha cercana de 1.200 d.C. de la Hacienda Manuel Rodríguez (Schiappacasse et al. 1991), lo que sumado a la datación de 1.320 d.C. para cerámica preincaica Pacajes o Carangas de Camarones, indica una ubicación de la alfarería altiplánica desde la sierra a los valles bajos posterior al 1.200 d.C. (Núñez 1984).

\section{El Período Tardío}

Finalmente, el Inka se manifiesta claramente en Cerro Esmeralda (Checura 1977), así también en contextos funerarios más bien costeros como los de Patillos y Caleta Huelén (Moragas 1995; Núñez 1971), hacia el interior en Tarapacá Viejo y los cementerios de Pica, igual que en espacios altiplánicos de Isluga y Collacagua (Niemeyer 1962b; L. Núñez 1984; P. Núñez 1984; Reinhard y Sanhueza 1982; Zlatar 1984). Con todo, no existe mayor caracterización de su alfarería durante la expansión del Tawantinsuyo hacia Tarapacá (Uribe 1999-2000, 2006b).

A partir de la colección de Cerro Esmeralda pudimos identificar vasijas restringidas y no restringidas (Checura 1977), distinguiéndose que la mayor variedad se concentra en las primeras, donde se observan ollas con pedestal, aríbalos, cántaros y jarros, mientras que las irrestrictas se reducen a platos bajos o escudillas. Todas muestran las típicas pastas del altiplano, arenosas muy compactas con cuarzo y biotita (mica), de cocción oxidante principalmente regular y colores anaranjado a café con diversos revestimientos y decorados en blanco o ante, rojo y negro.

Brevemente, se desprenden dos estilos incaicos principales que definimos como Cusco y Altiplano (Figura 5), pudiéndose distinguir a partir de estos últimos aquellos ejemplares Circumtiticaca y del Altiplano Meridional, destacando hacia el sur el tipo Inka Pacajes. Mientras que en el caso de la cerámica altiplánica central (posiblemente Lupacas y Collas) sobresalen lo que podría ser la variante Urcosuyo en Cerro Esmeralda e Isluga (Sanhueza 


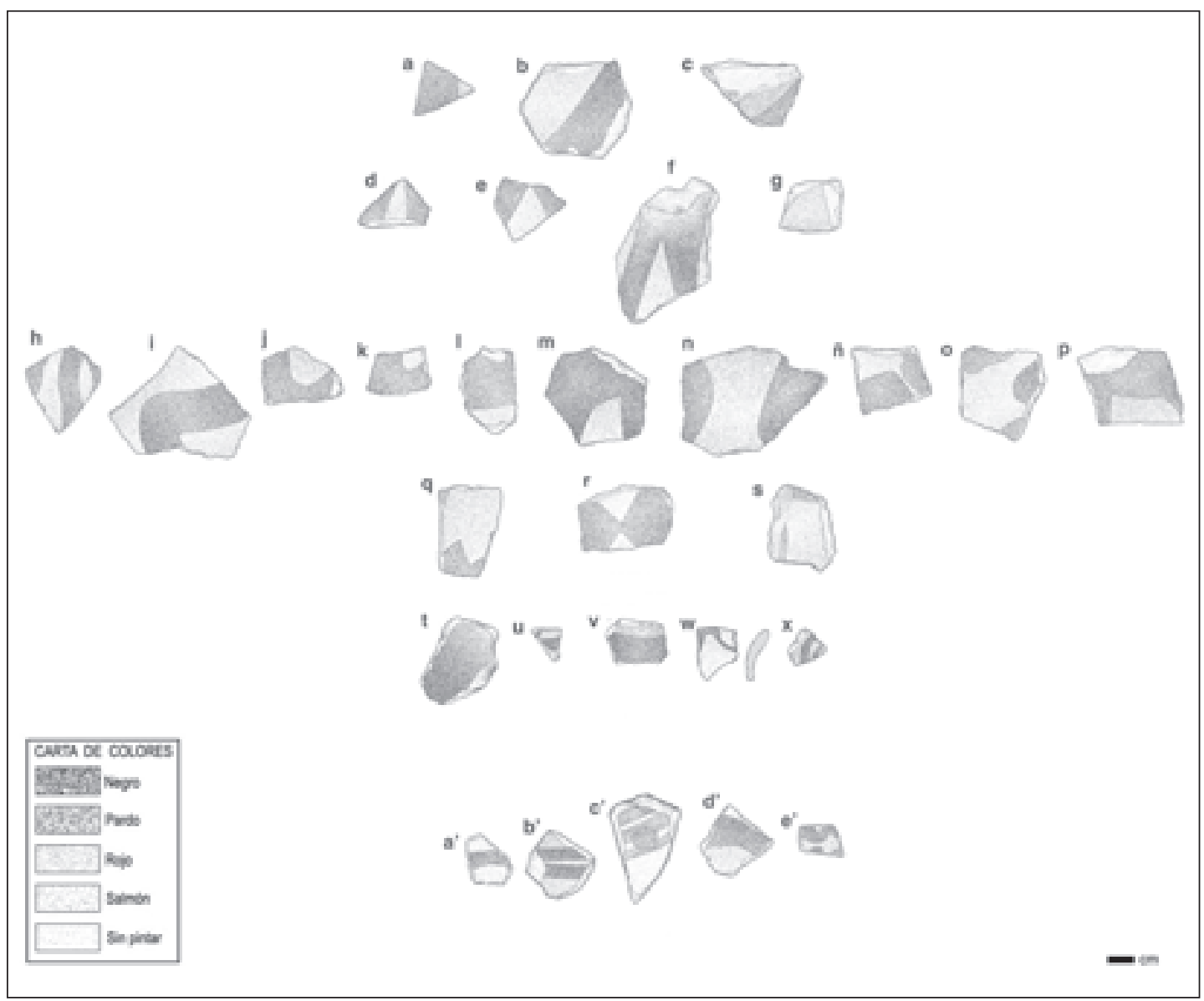

Figura 4. Componente cerámico Altiplano Tarapacá: (a-x) tipo Isluga Negro sobre Rojo ISL (decoración de líneas rectas, paralelas, divergentes, onduladas y triangulares en el exterior), sitios Nama (a-s) y Chusmisa (t-x) (Núñez 1965a); (a'-e') tipo Chilpe Negro sobre Rojo CHP (decoración de líneas rectas, paralelas, onduladas, triangulares y puntos en el interior), sitio Chusmisa. Escala $=1 \mathrm{~cm}$.

Altiplano Tarapacá ceramic component: (a-x) Isluga Black on Red ISL type (exterior surface decorated with different kind of lines, waves and triangles), Nama ( $a$-s) and Chusmisa ( $t-x)$ sites (Núñez 1965a); ( $\left.a^{\prime}-e^{\prime}\right)$ Chilpe Black on Red CHP type (interior surface decorated with different kind of lines, waves, triangles and points), Chusmisa site. Scale $=1 \mathrm{~cm}$.

y Olmos 1981), e incluso ejemplares Sillustani negro y rojo sobre ante o blanco identificados en los poblados de Pachica y Saguara en la sierra de Camarones (Rowe 1969; Schiappacasse et al. 1991; Tschopik 1946). Por su parte, el tipo Cusco Policromo con su decoración de figuras a modo de espigas y rombos con clepsidras o equis representaría la alfarería propiamente imperial en sus variantes A y B (Rowe 1969). En el adyacente altiplano de Carangas la cerámica incaica es bastante semejante a ésta de Iquique, pero además se mencionan piezas que podrían corresponder a estilos más meridionales y orientales de las tierras altas como Yavi del territorio Chichas (Michel 2000).
Cerca de nuestra región sólo contamos con fechados por termoluminiscencia del tipo Inka Altiplano en sus variantes Sillustani y Saxamar; la primera ubicada entre 1.420 y 1.560 d.C., y la segunda algo más temprana entre 1.350 y 1.400 d.C., pero cuyos sigmas positivos la centran durante el 1.400 d.C. (Schiappacasse et al. 1991). De lo anterior, destacamos una clara articulación tecnológica y estilística con la alfarería del altiplano, de la misma manera como se ha propuesto para el territorio Pacajes cuyos vínculos con el Inka se han establecido tempranamente por fechados de radiocarbono calibrados entre el 1.310 y 1.450 d.C. (Pärssinen y Siiriäinen 1997). 


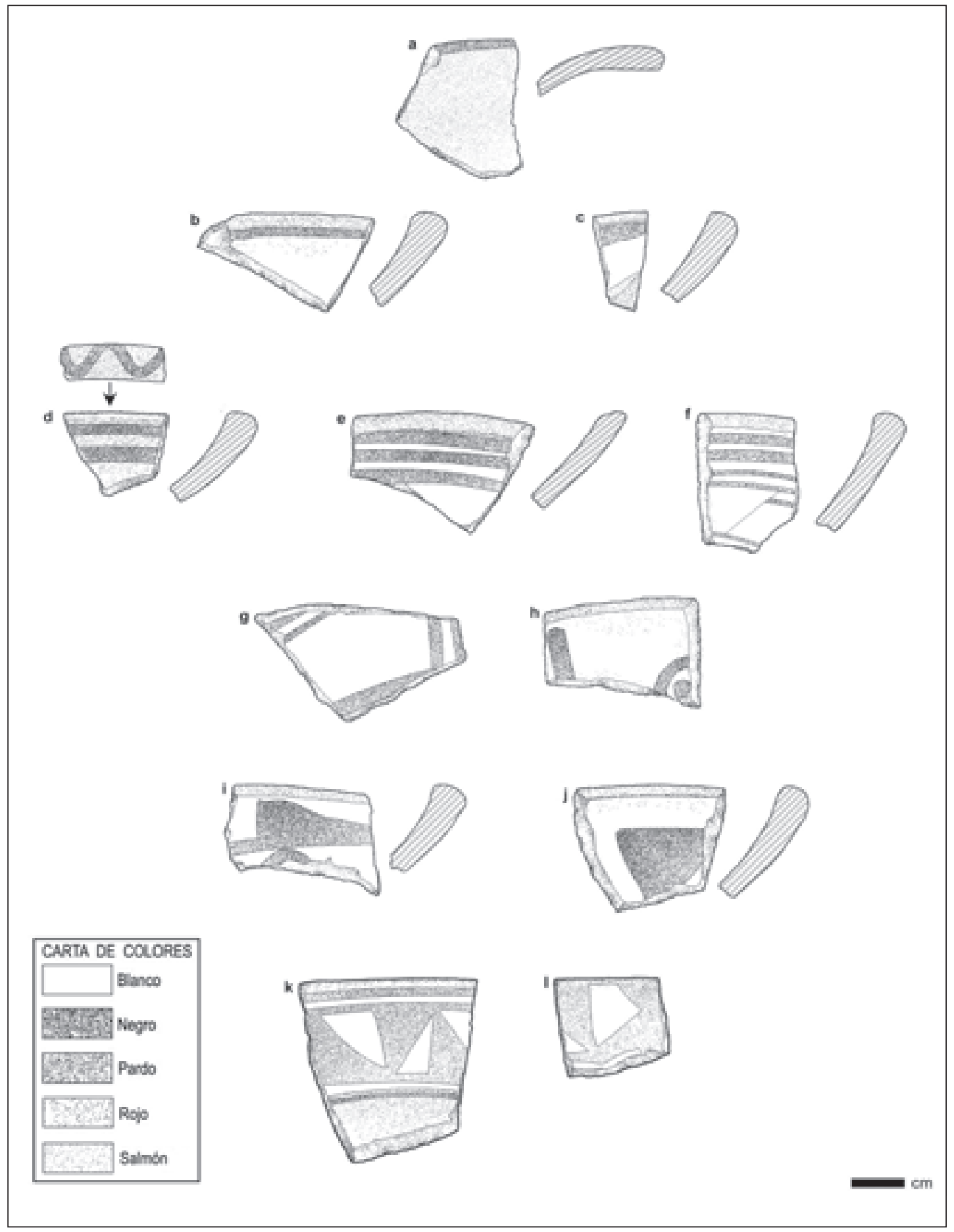

Figura 5. Componente cerámico Incaico: (a-j) tipo Inka Cusco Policromo INK (fragmentos de aríbalo y escudillas decorados en ante, blanco, negro y rojo), sitio Tarapacá 49 o Tr 49 (L. Núñez 1979; P. Núñez 1984); (k-1) Inka Altiplánico IKL (fragmentos de escudillas decoradas con motivos de aspas o variedad Urcosuyo), sitio Tarapacá 49 o Tr 49 (L. Núñez 1979; P. Núñez 1984). Escala $=1 \mathrm{~cm}$.

Inka ceramic component: (a-j) Inka Cusco Polyichrome INK type (fragments of aryballus and bowls decorated with cream, white, black and red), Tarapacá 49 or Tr 49 site (L. Núñez 1979; P. Núñez 1984); ( $k$-l) Inka Altiplano IKL type (bowl fragments decorated with triangles motifs named Urcosuyo), Tarapacá 49 or Tr 49 site (L. Núñez 1979; P. Núñez 1984). Scale = $1 \mathrm{~cm}$. 


\section{Análisis Tipológico, Cuantitativo y Espacial de la Cerámica de Tarapacá}

Conforme a estos antecedentes, análisis de laboratorio y trabajos de campo, clasificamos la cerámica y nos abocamos a evaluar la tipología expuesta a partir del análisis del material superficial y de excavaciones de los poblados del interior y la costa de Tarapacá. Se recolectó sistemáticamente el $10 \%$ de los sitios del interior entre los 1.200 y $3.300 \mathrm{msm}$, a través de un muestreo estratificado y dirigido de acuerdo a su diversidad arquitectónica y evitando espacios previamente trabajados, dando por resultado 12.744 fragmentos de cerámica de superficie. Camiña 1 es el sitio que presenta la mayor cantidad de materiales, correspondiente a 3.655 fragmentos de 62 recintos (620 estructuras); en Nama 1 se recolectaron 3.087 correspondientes a 53 recintos (558 estructuras); en Chusmisa 1.851 fragmentos de 12 recintos (137 estructuras); en Caserones 11.830 de 64 recintos (640 estructuras); en Tarapacá Viejo 1.726 fragmentos de 12 recintos (120 estructuras) y Jamajuga con 595 fragmentos de 15 recintos (150 estructuras). Para la costa, contamos con la cerámica de los sitios Pisagua $\mathrm{B}$ y $\mathrm{N}$ con cinco y 25 estructuras cada uno, donde se recuperaron sólo 406 fragmentos de superficie y excavaciones, 330 y 76 unidades provenientes de tres y siete recintos respectivamente. Finalmente, se incluye el material de las excavaciones en Caserones 1 y Camiña 1, donde se sondearon 17 y 13 estructuras que rindieron 972 y 5.040 fragmentos en cada caso, además de datos específicos de los otros sitios sondeados donde se recuperaron 2.678 unidades (Nama 1, Chusmisa y Jamajuga). Por lo tanto, la muestra total se encuentra constituida por 21.840 fragmentos.

Para el análisis estadístico del material, se consideraron tanto los tipos cerámicos individualmente como agrupados de acuerdo a su procedencia, adscripción cultural y temporalidad. Luego se trabajó con tablas de frecuencia, expresadas tanto en cantidades reales, así como en frecuencias relativas o porcentajes. La categoría Erosionados (ERO) no se consideró para la mayor parte del estudio, pues no representa ningún tipo cerámico propiamente tal, sino, por el contrario, una condición de alteración del fragmento que no permite una clasificación segura. Por último, con el objeto de establecer asociaciones significativas al interior como entre los asentamientos, de acuerdo a la presencia de los tipos cerámicos en ellos y su frecuencia, se realizaron análisis de agrupamiento por promedio de grupos de pares, no discriminatorio y distancia euclidiana utilizando el programa Statistica.

\section{Caracterización tipológica y espacial de la muestra}

En la muestra analizada se determinó la presencia de 28 clases cerámicas (Tabla 2), todas ellas correspondientes a tipos cerámicos seguros y algunos dudosos, junto con dos categorías residuales referidas a material Indeterminado (IND) y Erosionado (ERO). En primer lugar, se registró la presencia de los tipos Loa Café Alisado (LCA), Quillagua Tarapacá Café Amarillento (QTC), Quillagua Rojo Pulido (QRP1 y QRP2) ${ }^{4}$ y Caserones Negro Pulido (CNP), que agrupamos dentro de un componente temprano que se remontaría principalmente al período Formativo Tardío (ca. 500 a.C.-500 d.C.), donde también incluimos cerámica San Pedro Negra Pulida del Salar de Atacama (SNP). Luego, aparece una gran variedad de ejemplares tanto de las tierras bajas como altas que configuran los componentes Pica Tarapacá y Altiplano Tarapacá, constituidos por tipos no decorados y decorados, pertenecientes al período Intermedio Tardío local (ca. 900-1.450 d.C.). Dentro del primero, identificamos los tipos Pica Charcollo (PCH), Pica Gris Alisado (PGA) y Pica Chiza (PCZ); mientras que en el segundo distinguimos los tipos Isluga Negro sobre Rojo (ISL), Isluga Rojo Revestido (IRR), Isluga sin Decoración (ISD) y Chilpe Negro sobre Rojo (CHP), que adscribimos al altiplano Carangas. A ellos sumamos los tipos Taltape Negro sobre Blanco (TAL) y Hedionda Negro sobre Ante (HED), asignados al altiplano de Quillacas y Lípez. También registramos como parte del Intermedio Tardío los tipos San Miguel (SMB), Pocoma Gentilar (PG) y Arica No Decorado (AND) del valle de Azapa, así como los tipos Aiquina (AIQ) y Dupont (DUP) de Atacama (Uribe 1997, 1999b, 2002). Por otra parte, identificamos los tipos Inka Cusco Policromo (INK), Inka Altiplánico (IKL) y Saxámar o Inka Pacajes (SAX), junto con los tipos Yavi La Paya (YAV), Turi Rojo Revestido Pulido Ambas Caras (TPA), Lasana Café Rojizo Revestido y Pulido (LCE y LCP) de la subárea circumpuneña (Uribe 1999a), 
Tabla 2. Cuadro resumen de tipos cerámicos determinados en la muestra de sitios de Tarapacá, con sus respectivas adscripciones cronológicas, culturales y abreviaturas usadas en el texto.

Summary table with ceramic types identified in the sample of Tarapaca sites, with their respective chronological and cultural assignments and abbreviations used in the text.

\begin{tabular}{|c|c|c|c|}
\hline Período & Componente & & Tipos Cerámicos \\
\hline & & LCA & Loa Café Alisado \\
\hline $\begin{array}{c}\text { Formativo } \\
\text { ca. } 1.000-1.450 \text { d.C. } *\end{array}$ & $\begin{array}{c}\text { Formativo } \\
\text { Tardío } \\
\text { (ca. } 500 \text { A.C. }-500 \text { d.C. }{ }^{*} \text { ) }\end{array}$ & $\begin{array}{l}\text { QTC } \\
\text { QRP1 } \\
\text { QRP2 } \\
\text { CNP } \\
\text { SNP }\end{array}$ & $\begin{array}{l}\text { Quillagua Tarapacá Café Amarillento } \\
\text { Quillagua Rojo Pulido Restringido } \\
\text { Quillagua Rojo Pulido No Restringido } \\
\text { Caserones Negro Pulido } \\
\text { San Pedro Negro Pulido }\end{array}$ \\
\hline \multirow[t]{6}{*}{$\begin{array}{l}\text { Intermedio Tardío } \\
\text { ca. } 1.000-1.450 \text { d.C. }\end{array}$} & Pica Tarapacá & $\begin{array}{l}\text { PCH } \\
\text { PGA } \\
\text { PCZ }\end{array}$ & $\begin{array}{l}\text { Pica Charcollo } \\
\text { Pica Gris Alisado } \\
\text { Pica Chiza }\end{array}$ \\
\hline & $\begin{array}{l}\text { Altiplano Tarapacá } \\
\text { (Carangas) }\end{array}$ & $\begin{array}{l}\text { CHP } \\
\text { ISL } \\
\text { IRR } \\
\text { ISD }\end{array}$ & $\begin{array}{l}\text { Chilpe } \\
\text { Isluga Negro Sobre Rojo } \\
\text { Isluga Revestido Rojo } \\
\text { Isluga Sin Decoración }\end{array}$ \\
\hline & Altiplano Quillacas & TAL & Taltape \\
\hline & Altiplano Lípez & HED & Hedionda \\
\hline & Arica & $\begin{array}{l}\text { SMB } \\
\text { PG } \\
\text { AND }\end{array}$ & $\begin{array}{l}\text { San Miguel } \\
\text { Pocoma y Gentilar } \\
\text { Arica No Decorado }\end{array}$ \\
\hline & Atacama & $\begin{array}{l}\text { AIQ } \\
\text { DUP }\end{array}$ & $\begin{array}{l}\text { Aiquina } \\
\text { Dupont }\end{array}$ \\
\hline $\begin{array}{c}\text { Tardío } \\
\text { ca. } 1.470-1.532 \text { d.C. }\end{array}$ & Incaico & $\begin{array}{l}\text { INK } \\
\text { IKL } \\
\text { SAX } \\
\text { YAV } \\
\text { TPA } \\
\text { LCE } \\
\text { LCP }\end{array}$ & $\begin{array}{l}\text { Inka Cusco Policromo } \\
\text { Inka Altiplánico } \\
\text { Saxamar Inka Pacajes } \\
\text { Yavi La Paya } \\
\text { Turi Rojo Pulido Ambas Caras } \\
\text { Lasana Café Rojizo Revestido } \\
\text { Lasana Café Rojizo Pulido }\end{array}$ \\
\hline $\begin{array}{c}\text { Histórico } \\
\text { ca. } 1.532 \text { en adelante }\end{array}$ & Histórico-Etnográfico & $\begin{array}{l}\text { HIS } \\
\text { TCA } \\
\text { ETN }\end{array}$ & $\begin{array}{l}\text { Hispano } \\
\text { Turi Café Alisado } \\
\text { Etnográfico }\end{array}$ \\
\hline
\end{tabular}

* Fechas convencionales.

que agrupamos en un componente Incaico del período Tardío (ca. 1.450-1.536 d.C.). Finalmente, dentro de un componente Histórico, identificamos un tipo Hispano (HIS) ${ }^{5}$, el Turi Café Alisado (TCA) y otro propiamente Etnográfico (ETN), pertenecientes a momentos coloniales y recientes de amplia difusión (Uribe 1997, 2002). En consecuencia, todos estos conjuntos cerámicos defini- rían componentes prehispánicos e históricos locales y foráneos que remitirían a alfarería bastante típica y ampliamente distribuida por el territorio de Tarapacá, acompañada por otras expresiones del altiplano, Arica y Atacama, antes, durante y posterior a la presencia de los Inkas en la región. En términos generales, lo anterior implica que el material se reparte principalmente entre los compo- 
nentes Pica Tarapacá, Formativo y Altiplano Tarapacá, siendo predominante el primero que abarca cerca del $70 \%$ de la muestra, seguido por los componentes Formativo y Altiplano Tarapacá entre el 16 y $12 \%$ respectivamente (Figura 6). En cambio, el resto de los componentes apenas supera el $1 \%$.

El análisis de agrupamiento de acuerdo a las frecuencias relativas de su cerámica (Tabla 3 y Figura 7) muestra que si bien todos los sitios habitacionales estudiados fueron ocupados a lo largo del período Intermedio Tardío, éstos se separan claramente en dos subgrupos. Por un lado, los dos sitios de la costa y, por el otro, los del interior (valles bajos y quebradas altas). Los sitios de la costa se diferencian de los del interior por la dominancia de los tipos locales PCH, PGA y PCZ (67 a 80\%), característicos del componente Pica Tarapacá del Intermedio Tardío, y la casi total ausencia de los tipos Altiplano Tarapacá. No obstante, destaca la recurrencia de materiales de Arica, Atacama y un conjunto de fragmentos indeterminados. Los sitios Pisagua N y B, sin embargo, tienen importantes diferencias entre sí, dadas por las frecuencias de los tipos locales, entre los que destaca el tipo PCZ presente sólo en Pisagua B y una mayor variedad de tipos foráneos de Arica y Atacama en Pisagua N.

Por su parte, los sitios del interior presentan tres agrupaciones claramente diferenciables. Caserones 1 se distingue de los demás por presentar una importante frecuencia de tipos del Formativo Tardío (QTC y QRP=51\%), junto con los clásicos exponentes Pica Tarapacá (p.ej. tipo $\mathrm{PCH}=48 \%$ ). Acorde con esto, entonces, la diferencia está dada por un factor cronológico, coherente también con un emplazamiento distinto en el borde de la Pampa del Tamarugal, a diferencia de los otros asentamientos que están localizados al interior y en las quebradas altas. Así, con una marcada pertenencia al período Intermedio Tardío, los sitios Camiña 1 , Nama 1 , Chusmisa y Jamajuga muestran como común denominador la presencia conjunta de los tipos del Altiplano Carangas (ISL, ISR, ISD y CHP) en asociación con los del componente Pica Tarapacá (p.ej. tipo PCH=hasta 77\%), además de una consistente aunque escasa aparición de tipos no locales procedentes de Arica (AND, SMB y PG) y Atacama (AIQ, DUP). Al respecto, los sitios de Camiña y Nama son los que exhiben la mayor afinidad debido a la alta frecuencia del tipo
PCH (70\% y más) y la recurrencia de los tipos del altiplano Carangas (ISD, IRR y ISL=15 a 17\%), lo que puede ser considerado como lo más característico del desarrollo regional de Tarapacá. Chusmisa se separa de la agrupación anterior por presentar una proporción algo menor del tipo $\mathrm{PCH}$ $(62 \%)$, junto con una mayor importancia de los tipos altiplánicos CHP e IRR (16\%), la aparición del tipo IKL y otros como INK y SAX del período Tardío (4\%), que evidencian una ocupación que se extiende hasta tiempos posteriores, principalmente asociados a la presencia incaica en la región. Jamajuga, a su vez, se aleja un poco de los anteriores por la alta proporción del tipo ISD $(20 \%)$, por lo que aunque sigue siendo un típico representante del Intermedio Tardío, tiene un carácter todavía más altiplánico y tardío (p.ej. tipos TCA y LCE).

Por último, el sitio Tarapacá Viejo se distingue de los demás por una menor frecuencia del tipo PCH (33\%) y la importancia que adquiere el tipo IKL (30\%), que se asocia a otros tipos relacionados con la presencia incaica (p.ej. INK y SAX), ubicando a este sitio en la época más tardía de la secuencia prehispánica hasta alcanzar momentos coloniales por la existencia de alfarería colonial (HIS $=2 \%)^{6}$. Además, aquí destaca la mayor importancia de los tipos altiplánicos CHP e IRR $(17 \%)$ y la casi total ausencia de tipos foráneos procedentes de Atacama (salvo por expresiones incaicas circumpuneñas como el tipo TPA), aunque continúa la presencia de cerámica de Arica. En este sentido, parece relevante destacar la consistencia que presenta la presencia incaica en relación con los tipos cerámicos debido a la importancia de las clases IKL, INK, CHP e IRR, sugiriendo una mayor recurrencia de actividades relacionadas al Tawantinsuyo. Al mismo tiempo, la presencia de tipos asociados a tiempos coloniales (TCA e HIS) confirma la ocupación de Tarapacá Viejo en momentos tardíos y de contacto con el español, de la misma manera que la existencia de alfarería etnográfica $(\mathrm{ETN})$.

\section{Propuestas en Torno a la Historia Cultural del Complejo Pica Tarapacá}

La tipología y el comportamiento de la muestra dentro y entre los sitios estudiados nos permite proponer que los asentamientos y su alfarería representarían distintos momentos de la historia cul- 


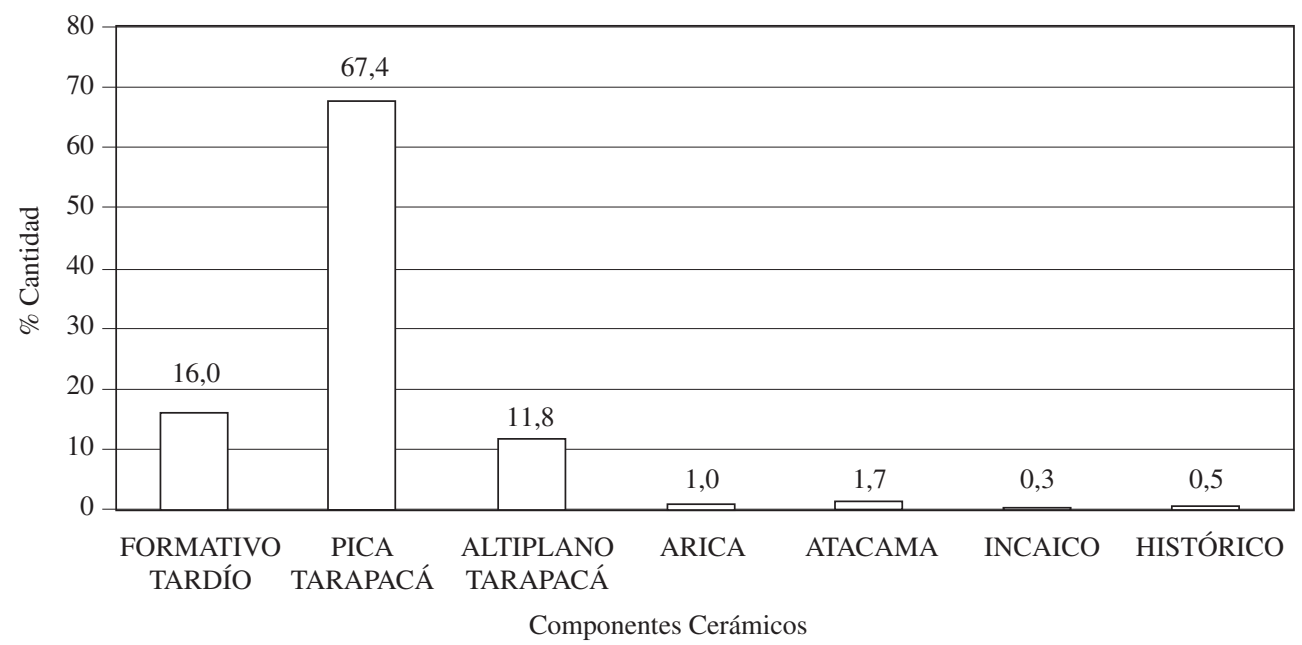

Figura 6. Gráfico con las frecuencias relativas de los componentes cerámicos presentes en los sitios de los valles bajos y quebradas altas de Tarapacá $(\%=$ cantidad $)$.

Graphic with relative frequencies of the ceramic components present in the sites of the low valleys and high ravines of Tarapacá (\%=quantity).

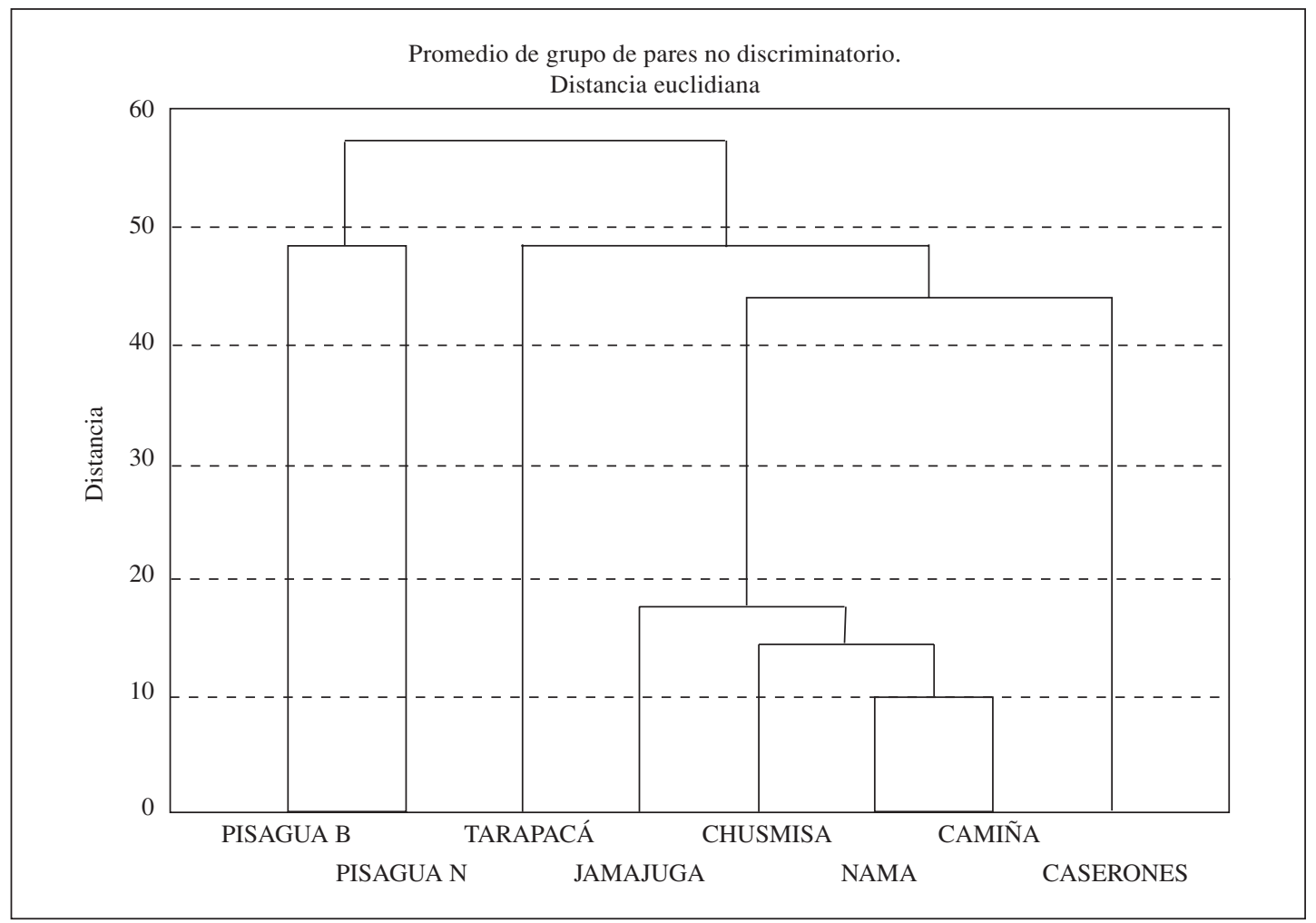

Figura 7. Gráfico del análisis de agrupamiento aplicado a la muestra de Tarapacá, mostrando las relaciones de distancia entre los sitios a partir de las frecuencias relativas de sus tipos cerámicos.

Graphic of the cluster analysis applied to the sample of Tarapaca that shows distance relationships between sites based on the relative frequencies of ceramic types. 


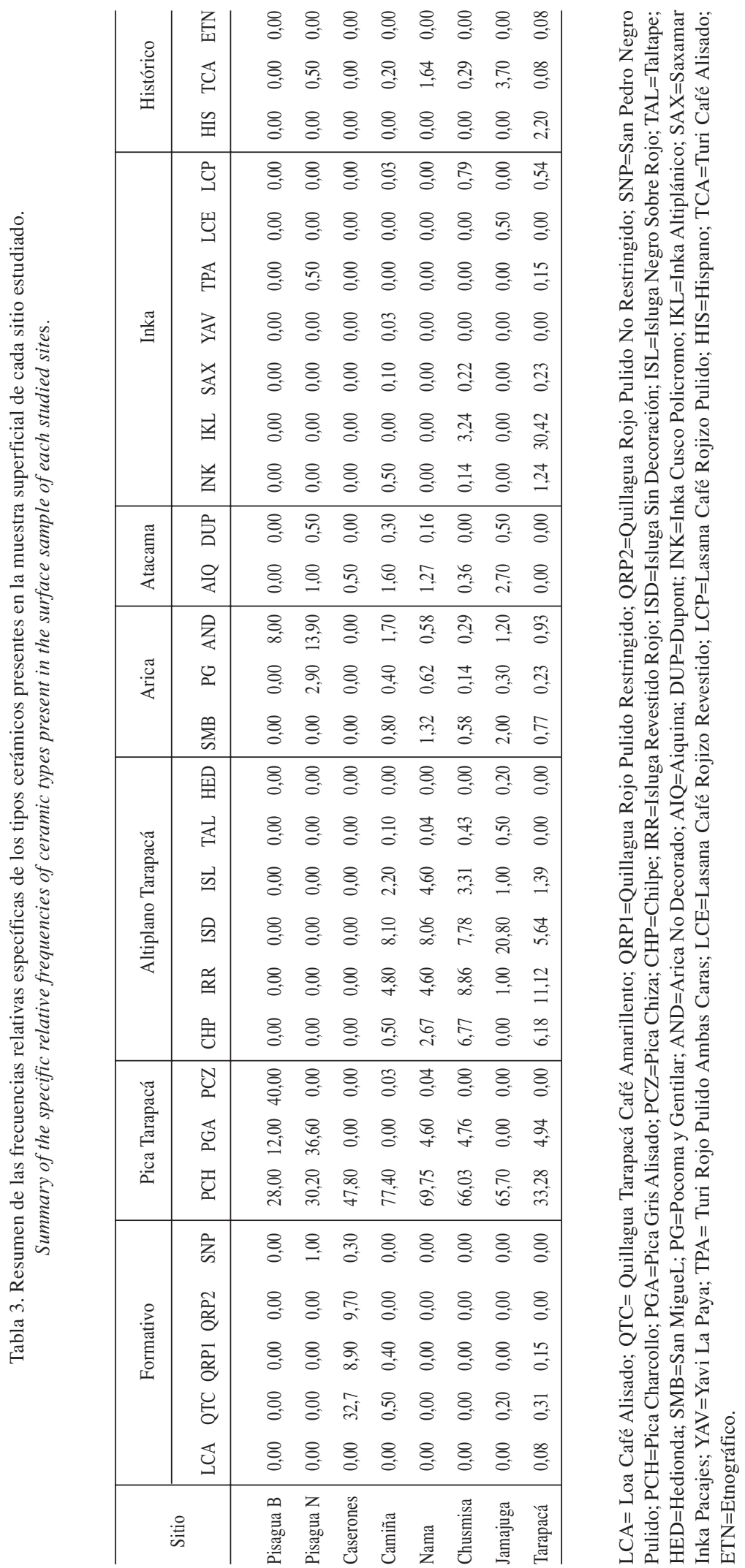


tural de Tarapacá, abarcando al menos desde el Formativo Tardío hasta la presencia Inka en el período Tardío (ca. 200-1.532 d.C.). Obviamente, la alta frecuencia del componente Pica Tarapacá en todos ellos indica que una de sus principales ocupaciones ocurrió durante el Intermedio Tardío (ca. 900-1.450 d.C.), vinculada con las poblaciones de la costa, valles bajos y quebradas altas en torno a la Pampa del Tamarugal, con un notorio núcleo en las quebradas tarapaqueñas (Uribe 2006a). Lo anterior se encuentra avalado por los fechados de termoluminiscencia obtenidos para los tipos Pica Charcollo y Pica Chiza, ubicando con seguridad estas cerámicas entre el 950 y 1.445 d.C. (Tabla 1). Al mismo tiempo, la relación con las evidencias formativas, altiplánicas e incaicas nos ayuda a establecer una secuencia más precisa para el desarrollo regional apoyada en los materiales superficiales, así como en las primeras excavaciones y dataciones absolutas que nosotros hemos realizado en la zona (Méndez-Quirós y Uribe 2006). Las que ejemplificamos principalmente por los casos de Caserones 1 y Camiña 1, a 1.200 y $3.300 \mathrm{msm}$, correspondientes a los valles bajos y quebradas altas de Tarapacá respectivamente.

La composición tipológica de Caserones 1 (Figura 8) evidencia una ocupación por parte de poblaciones locales que se extiende desde el Formativo Tardío hasta el período Intermedio Tardío, en su porción más temprana o inicial, ya que los componentes Altiplano Tarapacá, Incaico e Histórico no aparecen, sugiriendo un cambio en el sistema de asentamiento en tiempos prehispánicos. La distribución superficial de los tipos cerámicos de ambos períodos es muy homogénea en el sitio (51 y $48 \%$ respectivamente), dominado claramente lo local y una escasa variedad tipológica donde ambos componentes aparecen juntos casi en la totalidad de los recintos recolectados. De hecho, la presencia de materiales foráneos es mínima, evidenciando escasos nexos cerámicos con las regiones circundantes, que se remiten exclusivamente a Atacama y al Formativo ${ }^{7}$. Al interior de este último, el tipo alisado QTC es el que exhibe la mayor frecuencia (33\%) y también es el que se encuentra distribuido en una mayor cantidad de recintos $(90,6 \%)$. Los tipos pulidos QRP, en cambio, aparecen en una cantidad considerablemente menor (bajo el 10\%), pero su presencia es igualmente dispersa (60\% de las estructuras). Por su parte, el componente Pica Tarapacá del Interme- dio Tardío se encuentra representado sólo por el tipo $\mathrm{PCH}$, pero alcanza la mayor frecuencia en superficie (48\%) y una distribución en casi todos los recintos del sitio $(90,6 \%)$. Sus acotadas características tipológicas, por lo demás, recuerdan la situación de la costa debido al dominio del componente Pica Tarapacá en Pisagua B y N, sin perjuicio que los asentamientos se mantengan vigentes hasta momentos posteriores. De acuerdo con esto, sugerimos la existencia de al menos dos ocupaciones dentro de una continuidad cultural que tendría como base el período Formativo Tardío y que luego se desarrollaría en un primer momento del Intermedio Tardío, considerando que las principales fechas para la alfarería Pica Tarapacá tienden a concentrarse entre el 950 y 1.200 d.C. Más aún, en Pisagua B y N contamos con dataciones por termoluminiscencia de 290 y 960 d.C. para posibles cerámicas tarapaqueñas y atacameñas que perfectamente pueden ser ejemplares alisados y pulidos formativos como los que caracterizan a Caserones.

Nuestras excavaciones apoyan esta hipótesis, por cuanto en estratigrafía notamos un claro descenso del componente Pica Tarapacá $(26,2 \%)$ y el radical aumento de los tipos Formativos Tardíos sobre todo de los pulidos $(37,8 \%)$, destacando los tipos QRP, CNP e incluso un fragmento modelado Séquitor de San Pedro de Atacama (SNP). Esta observación coincide con las de Mavrakis (1985), quien destaca en su análisis del mismo sitio dos períodos ocupacionales. Compartimos con él la idea de un primer momento con una predominancia homogénea de tipos alisados, engobados, pulidos y bruñidos, especialmente en las capas intermedias e inferiores; seguido por una segunda etapa con muy poca cerámica pulida y un considerable aumento de los alisados hacia la superficie, casi desapareciendo el tipo CNP (Figura 9). Dicho cambio para el autor habría ocurrido entre el 600 y 800 d.C. (Mavrakis 1985:166), lo que a nuestro parecer, y de manera muy semejante a como previamente lo propuso True (1980) para el período 4 de Caserones, habría dado paso al Intermedio Tardío y su alfarería monocroma, café y estriada, desarrollándose de manera pura a partir del 950 d.C. de acuerdo a un fechado de radiocarbono no calibrado. Dichas apreciaciones hoy se encuentran corroboradas por otra fecha calibrada de los niveles superiores de Caserones de 890-1.020 cal. d.C. $(p=0,95)$ (calibrado a 2 sigmas con el programa 


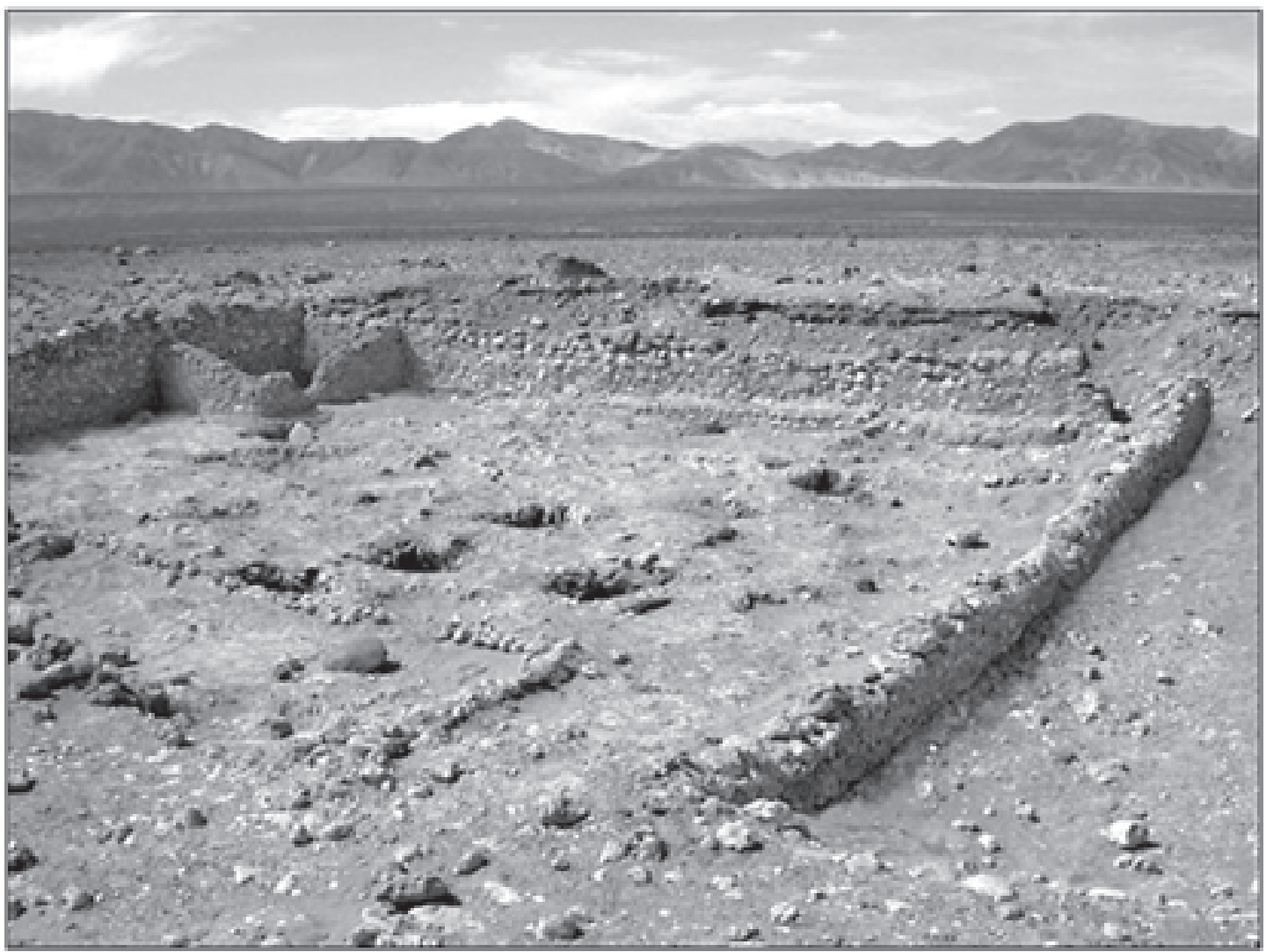

Figura 8. Vista del sitio Caserones 1 y su arquitectura residencial ortogonal, característica del período Formativo Tardío y ocupada hasta inicios del Intermedio Tardío (Adán et al. 2005; True 1980).

View of the Caserones 1 site and its domestic orthogonal architecture that is characteristic of the Late Formative Period and occupied until the beginning of the Late Intermediate Period (Adán et al. 2005; True 1980).

Intcal 98 de Stuiver et al. 1998). A ellas se suman las dataciones de Pisagua N de 1.030-1.250 d.C. $(p=0,95), 1.020-1.210$ d.C. de Camiña $1(p=0,95)$ y $1.160-1.290$ d.C. de Jamajuga $(p=0,95)$ (calibradas a 2 sigmas con el programa Intcal 98 de Stuiver et al. 1998) (Tabla 1), para contextos donde predominan las cerámicas Pica Tarapacá. Sin embargo, a diferencia de algunos de estos investigadores (Mavrakis 1985), no creemos que haya ocurrido un abandono repentino del asentamiento, de los valles bajos ni de la costa, debido a la gran proporción y alta dispersión del componente Pica Charcollo en la superficie de los sitios, sino un traslado gradual hacia otras zonas como los cursos altos de las quebradas, ya planteado por otros colegas (L. Núñez 1979; P. Núñez 1983) y evidente en los niveles inferiores de sitios como Tarapacá Viejo (P. Núñez 1984). Esto anunciaría una segunda etapa dentro del Intermedio Tardío que estaría mejor caracterizada en lugares altos como
Camiña 1 y sus símiles en Nama, Chusmisa y Jamajuga.

En Camiña 1 (Figura 10) aumenta notoriamente el material cerámico y su variedad, contabilizando hasta 500 fragmentos en algunos recintos, mostrando una ocupación exclusiva del Intermedio Tardío que topa con el período Tardío, pero sin mostrar la fortaleza del componente Incaico que luego se observa en Tarapacá Viejo. Asimismo, las evidencias del Formativo Tardío son mínimas, aunque continúan y siguen siendo expresiones propias de Tarapacá (tipos QTC y QRP). De hecho, las excavaciones muestran que la alfarería del Formativo alcanza su mayor frecuencia y variedad en las excavaciones $(2,1 \%)$, en tanto las cerámicas Incaica y posteriores se restringen a la superficie. Por otra parte, se agrega una importante presencia del componente Altiplano Tarapacá, especialmente del territorio Caranga, sugiriendo una intensa interacción que a diferencia de Case- 


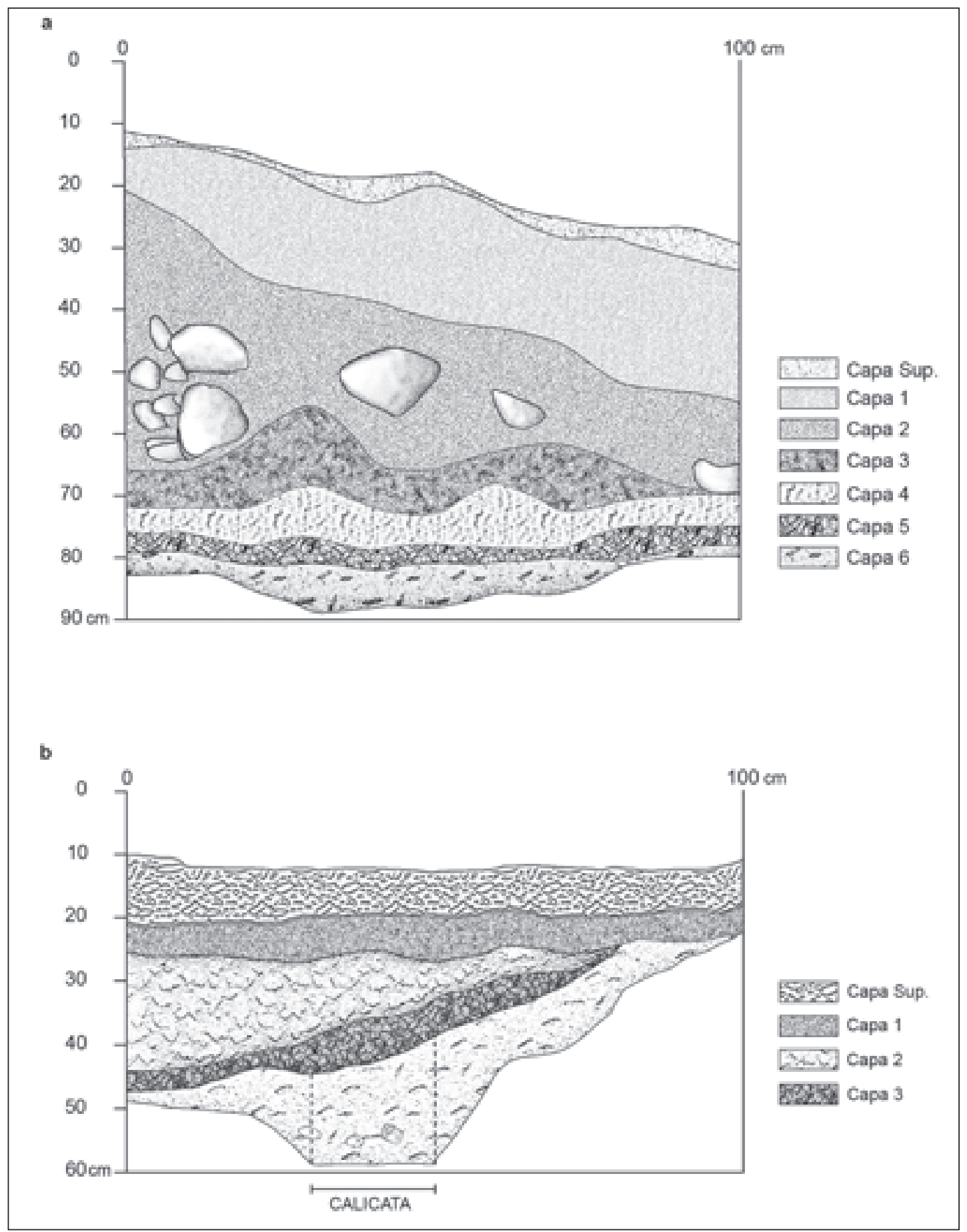

Figura 9. Reconstrucción de perfiles de excavación: (a) sitio Caserones 1 (recinto 516), donde se observan dos ocupaciones tempranas (capas 4 y 6) intercaladas por el desplome de techumbre (capa 5), cubiertas a su vez por derrumbe de muros y ocupaciones tardías (capas 1 y 2); (b) sitio Camiña 1 (recinto 250), donde se observan dos ocupaciones (capas 1 y 3 ), una temprana separada por el aterrazado para nivelar el piso de la ocupación tardía (capa 2).

Reconstruction of excavation profiles: (a) Caserones 1 site (enclosure 516) that shows two early occupations (levels 4 and 6) separated by a roof collapse (level 5), and both covered with the wallfall and late occupations (levels 1 and 2); (b) Camiña 1 site (enclosure 250) that shows two occupations (leves 1 and 3), an early one separated by a terrace to level the floor of the late occupation (level 2). 


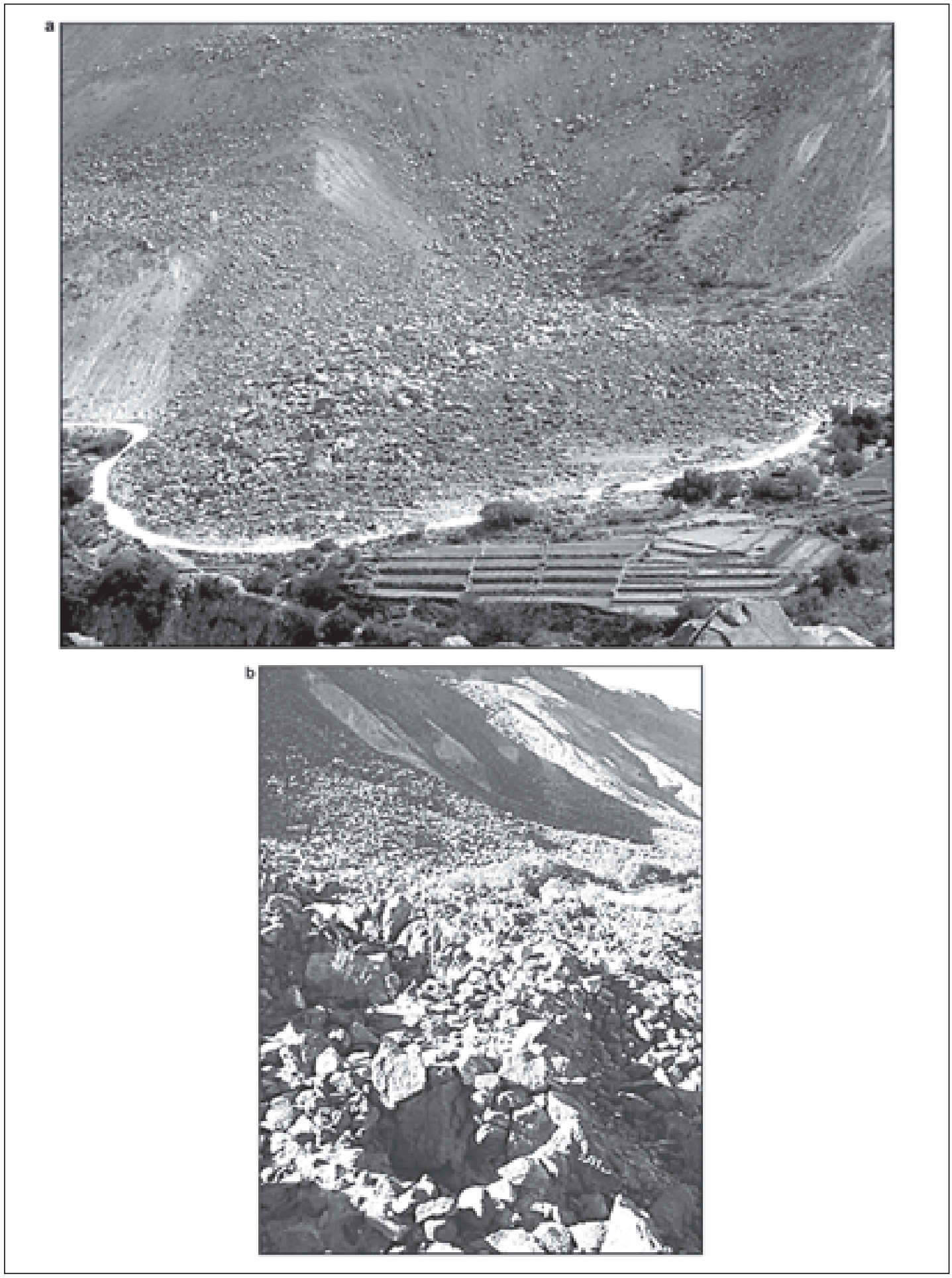

Figura 10. Vista del sitio Camiña 1 (a) y su arquitectura residencial circular (b), característica del período Intermedio Tardío, especialmente durante su desarrollo clásico y tardío (Adán et al. 2005).

View of the Camiña 1 site (a) and its domestic circular architecture (b) that is characteristic of the Late Intermediate Period, especially during its classic and late development (Adán et al. 2005). 
rones permite la introducción de cerámicas foráneas. Lo anterior además se ve expresado en la aparición de tipos del Altiplano Quillacas, de Atacama y Arica. De este modo, la distribución del componente Pica Tarapacá (p.ej. tipos PCH y PCZ) abarca prácticamente todo el sitio $(98,4 \%$ de las estructuras), aumenta de manera notable su frecuencia $(77 \%)$ y aparece asociado al componente Altiplano Tarapacá; éste, a su vez, tiene una presencia considerable (16\%) y una distribución igualmente amplia (67,7\% de los recintos), siendo frecuente que además aparezcan otros tipos foráneos. Esto sugiere que la principal ocupación se produjo con posterioridad al Formativo y en pleno desarrollo del Intermedio Tardío, denotando un segundo momento del período considerando los fechados para la alfarería altiplánica entre el 1.200 y 1.450 d.C. (L. Núñez 1984). Entonces, lo que nos interesa destacar es que en Camiña 1 se observa la continuación de la tradición cerámica tarapaqueña surgida a fines del Formativo, pero que se transforma radicalmente al incluir una considerable proporción de alfarería altiplánica, en especial Caranga, mostrando el clímax del desarrollo regional que no se aprecia en Caserones. Se constituye, entonces, un patrón cerámico que se extendería por el resto de las quebradas compartido por los sitios de Nama, Chusmisa y Jamajuga, sugiriendo una estrecha relación con las tierras altas.

De acuerdo a ello, nos parece importante dar cuenta que en Camiña 1 se pueden distinguir dos momentos propios del Intermedio Tardío, avalados tanto por el material superficial, de excavación así como por la arquitectura del asentamiento y sus fechados de radiocarbono (Adán et al. 2005). Al respecto, la cerámica de superficie permite distinguir un conjunto de estructuras que sólo presentan el componente Pica Tarapacá de manera dominante $(25 \%)$, concentradas en el sector norte; mientras que la mayoría de los recintos, sobre todo del lado sur, muestran el mismo predominio pero asociado al componente Altiplano Tarapacá y el resto de las cerámicas foráneas, e inclusive donde los tipos altiplánicos pueden aparecer solos. Más aún, en seis de las estructuras excavadas se observa que el componente Pica Tarapacá se concentra en los niveles inferiores y/ o en los recintos con una sola ocupación, mientras que en 14 de ellas aparece en conjunto con el componente Altiplano Tarapacá y el resto de la cerá- mica foránea, circunscritos a los niveles superiores (Figura 10). Tal situación se encuentra apoyada por la división de ambos espacios por un gran muro que atraviesa de este a oeste el asentamiento, los que rindieron fechas distintas. Así, un recinto del sector norte con exclusiva presencia del componente Pica Tarapacá se dató en 1.020-1.210 d.C. $(p=0,95)$, en tanto un recinto del sector sur donde se superpone al anterior el componente $\mathrm{Al}-$ tiplano Tarapacá fue fechado en 1.200 a 1.400 d.C. $(p=0,95)$ (calibradas a 2 sigmas con el programa Intcal 98 de Stuiver et al. 1998) (Tabla 1). En consecuencia, existirían al menos dos fases en la ocupación del sitio durante el período Intermedio Tardío y antes del Inka, configurando un comportamiento cerámico propio para momentos clásicos del desarrollo regional que combina los componentes Pica Tarapacá y Altiplano Tarapacá. $\mathrm{Al}$ respecto, contamos con una datación de 1.1601.310 y $1.370-1.380$ d.C. $(p=0,95)$ para Nama 1 y otra de 1.300-1.430 d.C. $(p=0,95)$ para Chusmisa (calibradas a 2 sigmas con el programa Intcal 98 de Stuiver et al. 1998) (Tabla 1), pertenecientes a contextos estratigráficos donde predominan las cerámicas altiplánicas. De este modo, no sólo los materiales de superficie sino también los de excavación de sitios de quebradas altas y la sierra confirmarían este nuevo patrón a partir de un momento posterior al 1.200 d.C. (Tabla 4), mostrando una gran homogeneidad caracterizada por la diversidad cerámica y un alejamiento de los vínculos formativos locales que aluden y avalan una complejidad social distinta que enfatiza la interacción interregional, especialmente con el Altiplano $(\mathrm{Ca}-$ rangas y Quillacas).

\section{Conclusiones}

Los estudios cerámicos han alcanzado gran legitimidad a lo largo de la historia de la arqueología $\mathrm{y}$, en particular, han demostrado su utilidad para la comprensión de la prehistoria del Norte Grande de Chile (p.ej. Dauelsberg 1972-1973; Tarragó 1976; Uribe 2004). Si bien estamos conscientes que la alfarería comprende una dimensión muy parcial de la conducta humana del pasado, su análisis permite un acercamiento a distintas dimensiones de la sociedad, dentro de las cuales la reconstrucción histórico cultural sigue teniendo un rol destacado (Espoueys et al. 1995; Muñoz y Chacama 1988; Schiappacasse et al. 1991). En este sentido, para 
Tabla 4. Cuadro resumen de presencias y ausencias de los componentes cerámicos Formativo Tardío, Pica Tarapacá y Altiplano Tarapacá, mostrando su distribución por fases y sectores en los recintos excavados de cada uno de los sitios estudiados.

Summary table of the presence and absence of Late Formative, Pica Tarapacá and Altiplano Tarapacá ceramic components, showing their distribution by phases and sectors in the excavated enclosures of each of the studied sites.

\begin{tabular}{|c|c|c|c|c|c|c|c|c|}
\hline Sitio & $\begin{array}{l}\text { Recintos } \\
\text { Excavados }\end{array}$ & $\begin{array}{c}\text { Formativo } \\
\text { Tardío }\end{array}$ & $\begin{array}{c}\text { Pica } \\
\text { Tarapacá }\end{array}$ & $\begin{array}{l}\text { Altiplano } \\
\text { Tarapacá }\end{array}$ & Arica & Atacama & Inka & Histórico \\
\hline \multirow{13}{*}{ Caserones } & 7 & 24 & 17 & & & & & \\
\hline & 126 & 13 & 9 & & & & & \\
\hline & 168 & 3 & 6 & & & & & \\
\hline & 247 & 3 & 3 & & & & & \\
\hline & 280 & 13 & 11 & & & & & \\
\hline & 298 & 22 & 16 & & & & & \\
\hline & 314 & 5 & 2 & & & & & \\
\hline & 357 & 27 & 16 & & & & & \\
\hline & 468 & 25 & 14 & & & & & \\
\hline & 516 & 9 & 11 & & & & & \\
\hline & 526 & 20 & 17 & & & & & \\
\hline & 593 & 4 & 2 & & & & & \\
\hline & 600 & 8 & 4 & 1 & & & & \\
\hline \multirow{17}{*}{ Camiña } & 52 & & 11 & 6 & 2 & 1 & & \\
\hline & 61 & 2 & 12 & 8 & 8 & 6 & & 1 \\
\hline & 119 & 3 & 23 & 10 & 11 & 3 & & 4 \\
\hline & 126 & 1 & 19 & 18 & 2 & 3 & & 1 \\
\hline & 139 & & 22 & 13 & 4 & 3 & & \\
\hline & 141 & 2 & 12 & 2 & 3 & 3 & & \\
\hline & 200 & 11 & & & 1 & & & \\
\hline & 215 & 12 & 15 & 2 & 1 & & & \\
\hline & 221 & 1 & 6 & & 2 & & & \\
\hline & 238 & 11 & 23 & 2 & & 3 & & \\
\hline & 250 & & 10 & 5 & 3 & 3 & & \\
\hline & 281 & & 9 & 3 & & 2 & & \\
\hline & 296 & & 6 & - & & 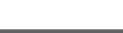 & & \\
\hline & 308 & & 8 & 1 & 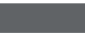 & 1 & & \\
\hline & 340 & 1 & 1 & 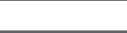 & 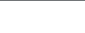 & - & & \\
\hline & 352 & & 13 & 1 & & & & \\
\hline & 381 & & 6 & 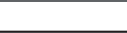 & & & & \\
\hline \multirow{4}{*}{ Chusmisa } & 28 & 1 & 12 & 11 & 3 & 3 & & \\
\hline & 89 & 2 & 19 & 20 & 1 & 3 & & \\
\hline & 97 & & 19 & 18 & & 2 & & 3 \\
\hline & 105 & & 6 & & & & & \\
\hline \multirow{5}{*}{ Jamajuga } & $5 \mathrm{~A}$ & 1 & 17 & 12 & 6 & & & \\
\hline & 39 & & 3 & 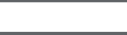 & & & 1 & 1 \\
\hline & 76 & & 17 & 15 & 8 & 2 & & 1 \\
\hline & 85 & & 23 & 11 & 6 & & & \\
\hline & 87 & & 5 & 1 & 1 & & 1 & 2 \\
\hline \multirow{13}{*}{ Nama } & 42 & & 3 & 2 & & & & 1 \\
\hline & 67 & & 12 & 10 & & 1 & & \\
\hline & 158 & & 5 & 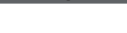 & & & & \\
\hline & 183 & & 7 & 4 & 2 & & & 3 \\
\hline & 192 & & 21 & 6 & 2 & 3 & & \\
\hline & 251 & & 17 & 11 & 2 & 3 & & 1 \\
\hline & 276 & & 6 & . & & & & 5 \\
\hline & 287 & & 35 & 11 & 5 & 3 & & 1 \\
\hline & 302 & & 7 & 1 & & & & \\
\hline & $338 \mathrm{~A}$ & & 10 & 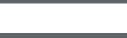 & & & & 5 \\
\hline & 344 & & 4 & 1 & & & & \\
\hline & 363 & & 6 & & & & & \\
\hline & 443 & & 1 & & & & & \\
\hline
\end{tabular}

Componente Formativo Tardío

Componente Pica Tarapacá y Fase Tarapacá

Componente Altiplano Tarapacá y Fase Camiña 
los Andes Centro Sur, acogemos el llamado de Pärssinen y Siiriäinen (1997) respecto a la necesidad de contar con más estudios detallados sobre esta materialidad para entender a cabalidad los procesos acaecidos entre el período Intermedio Tardío y la expansión del Inka en esta área. A propósito de dicha época y del llamado Horizonte Negro sobre Rojo, los autores plantean que:

\section{We are aware that our evidence is not yet conclusive; we certainly need additional radiocarbon and thermoluminescence dates from Cuzco and other Andean areas to establish more exactly the chronologi- cal sequence (Pärssinen y Siiriäinen 1997:266).}

Por lo tanto, a lo largo de este trabajo hemos demostrado que en tiempos prehispánicos tardíos en la región de Tarapacá se desarrolló una tradición cerámica monocroma y estriada, que durante el período Intermedio Tardío caracterizó la formación del denominado complejo cultural Pica Tarapacá como una entidad particular de los Valles Occidentales. Ésta abarcó desde la costa hasta la sierra, teniendo como núcleo los valles y quebradas del interior entre Camiña y Pica donde se percibe con mayor claridad la sumatoria de tradiciones y estilos cerámicos externos, concordante con un espacio propicio para la agricultura, ganadería, recolección y movimiento de bienes entre la costa y el altiplano, justo donde antes habitaron importantes concentraciones de población durante el Formativo (Núñez 1979, 1984; Uribe 2006a). Por lo que, a su vez, esta tradición de Tarapacá mostraría una clara continuidad cultural desde el Formativo Tardío y, a diferencia de Arica, sin mayor intervención de Tiwanaku, del todo ausente en los más de 21.000 fragmentos analizados de la costa, los valles bajos y quebradas altas. De hecho, sólo conocemos una vasija indiscutiblemente Tiwanaku, un par de piezas Cabuza y un ejemplar Yura Uruquilla o Yura Puqui registrados en Pica 8 (Zlatar 1984), este último asociado a un contexto funerario con cerámica Pica Tarapacá fechado por nosotros en 900-1.030 cal. d.C. $(p=0,95)$ (calibrado a 2 sigmas con el programa Intcal 98 de Stuiver et al. 1998) (Tabla 1), por lo que se trataría de expresiones terminales del Horizonte Medio (Céspedes y Lecoq 1998) ${ }^{7,8}$. Entonces, de acuerdo a este estudio sistemático de su alfarería, se confirma que el tipo Pica Charcollo y sus variantes son los principales representantes de Pica Tarapacá (Núñez 1965b; Ayala y Uribe 1996), con antecedentes en las cerámicas Quillagua y Tarapacá del Formativo Tardío (ca. 200-780 d.C. [Oakland 2000; Rivera 2002; True 1980]), manifestándose indiscutiblemente a lo largo de todo el Desarrollo Regional desde el 745/ 890 hasta el 1.450 d.C., confirmando planteamientos previos sobre un sofisticado desplazamiento de poblaciones y relaciones sociales entre el interior, la costa y viceversa (Moragas 1995; L. Núñez 1968, 1979, 1984; P. Núñez 1983; Sanhueza 1985).

Sin embargo, también damos cuenta de un panorama aún más complejo que permite distinguir con claridad dos momentos dentro del Intermedio Tardío no detectados antes en la región, si bien previamente vislumbrados por otros investigadores poco más al norte (Niemeyer y L. Núñez 1984; Schiappacasse 1981). Situación que, al mismo tiempo, conlleva una problematización de la previa aplicación de los clásicos modelos de verticalidad en los Andes Centro Sur; crítica a su mecánico uso que sólo enunciamos en esta oportunidad ya que mayores estudios para entender la naturaleza y dinámica de estos cambios todavía se hallan en curso. Por un lado, las características y exclusividad del componente Pica Tarapacá representaría un momento temprano entre el 745/890 y 1.250 d.C., evidenciando la continuidad entre las tradiciones alfareras formativas tardías y el desarrollo regional inicial, aludiendo a una complejidad social importante, manifiesta en su relación con notables formaciones aldeanas como Caserones (Adán et al. 2005) y en cementerios jerarquizados como los de Pica e Iquique (Pica 8, Bajo Molle, etc.); pero bastante circunscrita al ámbito local de la Pampa del Tamarugal y la costa, sin dejar de lado conexiones con Atacama seguramente a través del río Loa. En cambio, después del 1.250 d.C. las poblaciones Pica Tarapacá se vuelcan fuera de su territorio, pues tienden a manifestarse transformaciones ligadas a la introducción y circulación de cerámicas foráneas en los valles bajos y quebradas altas, sobre todo del Altiplano Meridional (Caranga y Quillaca); del mismo modo que piezas de los Valles Occidentales de Arica así como atacameñas del Loa y San Pedro. Este cambio sugiere una intensificación de la complejidad social que no parece ser satisfecha por la producción cerámica local como antes, al menos por la 
alfarería monocroma tradicional y quizás tampoco por la economía regional, conllevando a ampliar las redes de interacción así como el desplazamiento hacia tierras más altas tras la búsqueda de bienes suntuarios y/o productos básicos como los ganaderos (Núñez 1979). Así, en la sierra tarapaqueña se manifestarían cerámicas altiplánicas preincaicas a partir del 1.200 y 1.300 d.C., donde los tipos Isluga y Chilpe se convertirían en la principal alfarería del componente Altiplano Tarapacá, estableciéndose vínculos estilísticos con otras cerámicas como Kollau, Pacajes y Taltape (Albarracín-Jordán 1996; Dauelsberg 1972-1973; Lecoq 1991, 1999; Rydén 1947), si bien el nexo principal sería con el espacio Caranga (Michel 2000; Sanhueza y Olmos 1981). De acuerdo a ello, la introducción de cerámica decorada altiplánica como valluna e incluso circumpuneña podría referir a bienes insertos en relaciones de cooperación e intercambio y expresar la configuración de una trama social distinta, apoyada en los nexos externos y nuevas competencias sociales. Al mismo tiempo, esto incluso pudo provocar movimientos considerables de poblaciones hacia y desde la sierra, considerando que el componente Altiplano Tarapacá adquiere una gran representación en los asentamientos de Nama, Camiña, Chusmisa, Jamajuga y también Mocha (Moragas 1991). Y, producto de ello, se observaría una ocupación dual y compartida de este espacio por grupos de valles, quebradas y altiplano, sin perder el contacto con la Pampa y la costa (Schiappacasse et al. 1989).

Sin embargo, a diferencia de otros autores, no podemos asegurar que esta situación sea el producto de colonias manejadas por cabeceras altiplánicas o un intercambio institucionalizado dirigido por especialistas caravaneros (Niemeyer y
Schiappacasse 1981; L. Núñez 1984), puesto que la alfarería insinúa una conducta más versátil donde los valles bajos tienen un papel protagónico y cuyas poblaciones se integran con su cerámica a las redes de las tierras altas y la costa, ofreciendo alternativas diversas como las que actualmente se proponen para otros puntos de los Valles Occidentales (Santoro et al. 2004). Pero, sin perjuicio de esta última propuesta que enfatiza lo étnico e igualitario, nuestro estudio vislumbra una complejidad social mayor, por lo cual mantenemos este apelativo para denominar al desarrollo cultural tarapaqueño. En suma, proponemos que el complejo Pica Tarapacá se gestó durante el Intermedio Tardío, al menos en dos fases, una inicial y otra clásica; que de acuerdo a los sitios que ejemplifican la situación, las denominamos fase Tarapacá (ca. 900-1.250 d.C.) y Camiña (ca. 1.2501.450 d.C.) respectivamente, siendo este último el panorama que predominaría a la llegada del Inka a la región hasta 1.532 d.C.

Agradecimientos: Este trabajo es resultado del proyecto FONDECYT 1030923. Por lo tanto, agradecemos a las colegas Leonor Adán, Carolina Agüero, Cora Moragas y Flora Vilches por su compromiso con esta investigación. Asimismo, a todos quienes han participado del proyecto en terreno y laboratorio y a Paulina Chávez por las ilustraciones. También agradecemos los valiosos comentarios y observaciones de los evaluadores que contribuyeron a mejorar sobremanera la calidad de este artículo. Finalmente, gracias al profesor Luis Cornejo y a los estudiantes de arqueología de la Universidad de Chile, así como a las comunidades locales de Tarapacá por su apoyo y comprensión a la investigación científica.

\section{Referencias Citadas}

Adán, L. y S. Urbina

2004 Historia arquitectónica de la localidad de Pisagua (I Región, Chile): una tradición olvidada en los períodos tardíos del área Pica-Tarapacá. Ponencia presentada en XV Congreso Nacional de Arqueología Argentina, Río Cuarto.

Adán, L., S. Urbina y M. Uribe

2005 Arquitectura pública y doméstica en las quebradas de Tarapacá: asentamiento y dinámica social en el Norte Grande de Chile. Ponencia presentada en Taller Procesos Sociales Prehispánicos en los Andes Meridionales, Tilcara.
Agüero, C.

1998 Estilos textiles de Atacama y Tarapacá presentes en Quillagua durante el período Intermedio Tardío. Boletín del Comité Nacional de Conservación Textil 3:103-128. 2006 El Vestuario en la Conformación y Consolidación de la Identidad Cultural de las Poblaciones de Tarapacá durante el Período Intermedio Tardío. Tesis para optar al grado de Magíster en Arqueología, Universidad Católica del Norte-Universidad de Tarapacá, San Pedro de Atacama. Agüero, C., M. Uribe, P. Ayala y B. Cases

1997 Variabilidad textil durante el período Intermedio Tardío en el valle de Quillagua: una aproximación a la etnicidad. Estudios Atacameños 14:263-290. 
1999 Una aproximación arqueológica a la etnicidad: el rol de los textiles en la construcción de la identidad cultural en los cementerios de Quillagua (Norte de Chile). Gaceta Arqueológica Andina 25:167-198.

Agüero, C., M. Uribe, P. Ayala, B. Cases y C. Carrasco 2001 Ceremonialismo del período Formativo en Quillagua, Norte Grande de Chile. Boletín de la Sociedad Chilena de Arqueología 32:24-34.

Albarracín-Jordán, J.

1996 Tiwanaku. Arqueología Regional y Dinámica Segmentaria. CID/Plural Producciones, La Paz.

Aldunate, C. y V. Castro

1981 Las Chullpas de Toconce y su Relación con el Poblamiento Altiplánico en el Loa Superior. Tesis para optar al grado de Licenciado en Filosofía, Mención Prehistoria y Arqueología, Universidad de Chile, Santiago.

Aufderheide, A., M. Kelley, M. Rivera, L. Gray, L. Tieszen,

E. Iversen, R. Krouse y A. Carevic

1994 Contributions of chemical dietary reconstruction to the assessment of adaptation by ancient highland immigrants (Alto Ramírez) to coastal conditions at Pisagua, North Chile. Journal of Archaeological Science 21:515-524.

Ayala, P.

2001 Las sociedades formativas del Altiplano Meridional y su relación con el Norte Grande de Chile. Estudios Atacameños 21:7-39.

Ayala, P. y M. Uribe

1996 Caracterización de dos tipos cerámicos ya definidos: Charcollo y Chiza Modelado. Boletín de la Sociedad Chilena de Arqueología 22:24-28.

Bird, J.

1943 Excavations in Northern Chile. Anthropological Papers of the American Museum of Natural History XXXVIII(4), Nueva York.

Cervellino, M. y F. Téllez

1980 Emergencia y desarrollo de una aldea prehispánica de Quillagua, Antofagasta. Contribución Arqueológica 1, Museo Regional de Atacama, Dirección de Bibliotecas, Archivos y Museos, Copiapó.

Céspedes, R. y P. Lecoq

1998 El horizonte medio en los Andes Meridionales de Bolivia (Potosí). En Los Desarrollos Locales y sus Territorios. Arqueología del NOA y sur de Bolivia, compilado por B. Cremonte, pp. 103-129. Universidad Nacional de Jujuy, Jujuy.

Checura, J.

1977 Funebria incaica en el cerro Esmeralda (Iquique, I Región). Estudios Atacameños 5:125-141.

Dauelsberg, P.

1972-1973 La cerámica de Arica y su situación cronológica. Chungara 1-2:17-24.

1984 Taltape: definición de un tipo cerámico. Chungara 12:19-39.

Espoueys, O., M. Uribe, A. Román y A. Deza

1995 Nuevos fechados por termoluminiscencia para la cerámica del período Medio en el valle de Azapa (Primera Parte). Actas del XIII Congreso Nacional de Arqueología Chilena. Hombre y Desierto Una Perspectiva Cultural Tomo 2:31-53.
Gallardo, F., L. Cornejo, R. Sánchez, B. Cases, A. Román y

A. Deza

1991 Una aproximación a la cronología y el asentamiento en el oasis de Quillagua (río Loa, II Región). Actas XII Congreso Nacional de Arqueología Chilena. Boletín del Museo Regional de la Araucanía Tomo 2:41-60.

Heras y Martínez, C.

1992 Glosario terminológico para el estudio de las cerámicas arqueológicas. Revista Española de Antropología Americana 22:9-34.

Latcham, R.

1938 Arqueología de la Región Atacameña. Prensas de la Universidad de Chile, Santiago.

Lecoq, P.

1991 Sel et Archéologie en Bolivie: de Quelques Problemes Relatifs a l'Occupation de la Cordillère Intersalar (Sud Ouest Bolivien). Tesis Doctoral, Universidad de París, París.

1999 Uyuni Prehispanique. Archéologie de la Cordillère Intersalar (Sud-Ouest Bolivien). BAR International Series 798, Oxford.

Lecoq, P. y R. Céspedes

1997 Panorama archéologique des zones meridionales de Bolivia (Sud-Est de Potosí). Bulletin de l'Institute Français d'Etudes Andines 26:21-61.

Mavrakis, R.

1985 Análisis Tipológico Morfológico de la Cerámica de Caserones (1 ${ }^{a}$ Región, Chile). Memoria para optar al título de Arqueólogo, Universidad del Norte, Antofagasta.

Méndez-Quirós, P. y M. Uribe

2006 Análisis estratigráfico y cronología del complejo cultural Pica-Tarapacá (950-1.450 d.C.). Ponencia presentada en XVII Congreso Nacional de Arqueología Chilena, Valdivia.

Michel, M.

2000 El Señorío Prehispánico de Carangas. Diplomado Superior en Derecho de los Pueblos Indígenas, Universidad de la Cordillera, La Paz.

Moragas, C.

1991 Antecedentes sobre un Pukara y estructura de cumbre asociadas a un campo de geoglifos en la quebrada de Tarapacá, área de Mocha, I Región. Actas XII Congreso Nacional de Arqueología Chilena. Boletín del Museo Regional de la Araucanía Tomo 2:25-39.

1995 Desarrollo de las comunidades prehispánicas del litoral Iquique-desembocadura río Loa. Actas XIII Congreso Nacional de Arqueología Chilena. Hombre y Desierto Una Perspectiva Cultural Tomo 1:65-80.

2004 Reconocimiento arqueológico en el litoral de Pisagua, I Región. Manuscrito en posesión del autor.

Muñoz, I.

1989 El período Formativo en el Norte Grande (1000 a.C. a 500 d.C.). En Culturas de Chile. Prehistoria, desde sus Orígenes hasta los Albores de la Conquista, editado por J. Hidalgo, V. Schiappacasse, H. Niemeyer, C. Aldunate e I. Solimano, pp. 107-128. Editorial Andrés Bello, Santiago.

2004 El período Formativo en los valles del norte de Chile y sur de Perú: Nuevas evidencias y comentarios. Chungara Revista de Antropología Chilena. Volumen Especial, Tomo 1:213-225. 
Muñoz, I. y J. Chacama

1988 Cronología por termoluminiscencia para el período Intermedio Tardío y Tardío en la sierra de Arica. Chungara 20:19-46.

Niemeyer, $\mathrm{H}$.

1959 Excavaciones en Pica (Provincia de Tarapacá). Boletín del Museo y Sociedad Arqueológica de La Serena 10:59-68.

1961 Excursiones a la sierra de Tarapacá. Arqueología, toponimia, botánica. Revista Universitaria XLVI:97-114.

1962a Nuevas excavaciones en Pica, cementerio de Santa Rosita. Boletín del Museo y Sociedad Arqueológica de La Serena 12:7-17.

1962b Tambo incaico en el valle de Collacagua (Provincia de Tarapacá). Revista Universitaria XLVII (25):127-141.

Niemeyer, H. y V. Schiappacasse

1981 Aportes al conocimiento del período Tardío del extremo norte de Chile: análisis del sector Huancarane del valle de Camarones. Chungara 7:3-104.

Núñez, L.

1965a Prospección arqueológica en el Norte de Chile. Estudios Arqueológicos 1:9-36.

1965b Desarrollo cultural prehispánico del Norte de Chile. Estudios Arqueológicos 1:37-115.

1967-68 Figurinas tempranas del norte de Chile (Provincia de Tarapacá). Estudios Arqueológicos 3-4:85-105.

1968 Subárea Loa-costa chilena desde Copiapó a Pisagua. Actas XXXVII Congreso Internacional de Americanistas Tomo 2, pp. 145-182. Buenos Aires.

1970 Algunos problemas del estudio del Complejo arqueológico Faldas del Morro, Norte de Chile. Abband Berich des Staa mus Volker Dresden Bond 31:79-109.

1971 Secuencia y cambio en los asentamientos humanos de la desembocadura del río Loa en el Norte de Chile. Boletín de la Universidad de Chile 112:3-25.

1979 Emergencia y desintegración de la sociedad tarapaqueña: riqueza y pobreza de una quebrada del norte de Chile. Atenea 439:163-213.

1982 Temprana emergencia de sedentarismo en el desierto chileno. Proyecto Caserones. Chungara 9:80-122.

1984 Tráfico de Complementariedad de Recursos Entre las Tierras Altas y el Pacífico en el Área Centro Sur Andina. Tesis Doctoral, Universidad de Tokio, Tokio.

Núñez, L. y C. Moragas

1983 Cerámica temprana en Cáñamo (costa desértica del Norte de Chile): análisis y evaluación regional. Chungara 11:31-61.

Núñez, $\mathrm{P}$

1983 Aldeas tarapaqueñas, notas y comentarios. Chungara 10:29-37.

1984 La antigua aldea de San Lorenzo de Tarapacá, Norte de Chile. Chungara 13:53-66.

Oakland, A.

2000 Andean textiles from village and cemetery: Caserones in the Tarapacá valley, northern Chile. En Beyond cloth and Cordage, Archaeological Textile Research in the Americas, editado por P. Drooker y I. Webster, pp 229251. The University of Utah Press, Salt Lake City.

Pärssinen, M. y A. Siiriäinen

1997 Inka-style ceramics and their chronological relationship to the inka expansion in the southern Lake Titicaca area (Bolivia). Latin American Antiquity 8:255-271.
Ponce, $\mathrm{C}$.

1961 Breve comentario acerca de los fechados radiocarbónicos en Bolivia. Actas Encuentro Arqueológico Internacional de Arica, pp. 1-20. Boletín del Museo Regional, Arica.

Reinhard, J. y J. Sanhueza

1982 Expedición arqueológica al altiplano de Tarapacá y sus cumbres. CODECI 2:18-42.

Rivera, $\mathrm{M}$.

1988-89 Cerámicas tempranas de la costa Norte de Chile. Paleoetnológica 5:165-172.

2002 Historias del Desierto. Arqueología del Norte de Chile. Editorial del Norte, La Serena.

Rowe, J.

1969 An Introduction to the Archaeology of Cusco. Papers of Peabody Museum of American Archaeology and Ethnology 27(2), Harvard University, Cambridge.

Rydén, $\mathrm{S}$.

1947 Archaeological Researches in the Highlands of Bolivia. Elanders Boktryckeri Aktiebolag, Goteburgo.

Sanhueza, J.

1981 Antecedentes preliminares y dos fechas de radiocarbón del sitio Pukar Qollu o Pukara de Isluga, Altiplano de Iquique, I Región, Norte de Chile. Documentos de Trabajo 8:32-41.

1985 Poblaciones tardías en playa Los Verdes, costa sur de Iquique, I Región, Chile. Chungara 14:45-60.

Sanhueza, J. y O. Olmos

1981 Usamaya 1, cementerio indígena de Isluga, Altiplano de Iquique, I Región, Chile. Chungara 8:169-207.

Santoro, C., A. Romero, V. Standen y A. Torres

2004 Continuidad y cambio en las comunidades locales, período Intermedio Tardío y Tardío, valles occidentales del área Centro Sur Andina. Actas XV Congreso Nacional de Arqueología Chilena. Chungara Revista de Antropología Chilena. Volumen Especial, Tomo 1:235-247.

Schaedel, R. y C. Munizaga

1957 Arqueología Chilena: Contribuciones al Estudio de la Región Comprendida entre Arica y La Serena. Centro de Estudios Antropológicos, Universidad de Chile, Santiago.

Schiappacasse, V., V. Castro y H. Niemeyer

1989 Los desarrollos regionales en el Norte Grande. En Culturas de Chile. Prehistoria, desde sus Orígenes hasta los Albores de la Conquista, editado por J. Hidalgo, V. Schiappacasse, C. Aldunate e I. Solimano, pp.181-220. Editorial Andrés Bello, Santiago.

Schiappacasse, V., A. Román, I. Muñoz, A. Deza y G. Focacci 1991 Cronología por termoluminiscencia de la cerámica del extremo Norte de Chile: primera parte. Actas XI Congreso Nacional de Arqueología Chilena Tomo 1, pp. 43-60. Museo Nacional de Historia Natural, Santiago.

Sinclaire, C., M. Uribe, P. Ayala y J. González

1998 La alfarería del período Formativo en la región del Loa Superior: sistematización y tipología. Actas XIV Congreso Nacional de Arqueología Chilena Contribución Arqueológica Tomo 2:285-314.

Spahni, J.C.

1967 Recherches archéologiques a l'embouchure du Rio Loa (côte du Pacifique Chili). Journal de la Société des Américanistes 56:179-239. 
Stuiver, M., R. Reiner, E. Bard, J. Warrenbeck, G.S. Burr, C. Hughen, B. Kromer, G. McCormac, J. van der Plicht y M. Spurk

1998 Radiocarbon age calibration, $24.000-0$ cal b.p. $R a-$ diocarbon 40:1041-1083.

True, D.L.

1980 Archaeological investigations in Northern Chile: Caserones. En Prehistoric Trails of Atacama: Archaeology of Northern Chile, editado por C.W. Meighan y D.L. True, pp. 139-178. Monumenta Archaeologica 7, The Institute of Archaeology, University of California, Los Ángeles.

Tarragó, M.

1976 Alfarería típica de San Pedro de Atacama. Estudios Atacameños 4:37-73.

Tschopik, M.

1946 Some Notes on the Archaeology of the Department of Puno. Peabody Museum Papers 27(3). Cambridge, Massachusetts.

Uhle, M.

1919 La arqueología de Arica y Tacna. Boletín de la Sociedad Ecuatoriana de Estudios Históricos Americanos III (7-8):1-48.

Uribe, $M$.

1997 La alfarería de Caspana y su relación con la prehistoria tardía del área circumpuneña. Estudios Atacameños 14:243-262.

1999a La cerámica de Arica 40 años después de Dauelsberg. Chungara Revista de Antropología Chilena 31:189-228.

1999b La alfarería inca de Caspana. Boletín de la Sociedad Chilena de Arqueología 27:11-19.
1999-2000 La arqueología del Inka en Chile. Revista Chilena de Antropología 15:63-97.

2002 Sobre alfarería, cementerios, fases y procesos durante la prehistoria tardía del desierto de Atacama (800-1600 d.C.). Estudios Atacameños 22:7-31.

2004 Alfarería, Arqueología y Metodología. Aporte y Proyecciones de los Estudios Cerámicos del Norte Grande de Chile. Tesis para optar al grado de Magíster en Arqueología, Universidad de Chile, Santiago.

2006a Arqueología de Pica-Tarapacá (Norte de Chile): Reflexiones acerca de la complejidad y desigualdad social en los Andes Centro Sur (1000-1450 DC). Estudios Atacameños 31:91-114.

2006b De la periferia a los núcleos: cerámica, caminos y asentamientos en el altiplano de Tarapacá. Ponencia presentada en XVII Congreso Nacional de Arqueología Chilena, Valdivia.

Uribe, M. y L. Adán

2005 Evolución social a través de la prehistoria tardía de Pica-Tarapacá (Norte Grande de Chile). Ponencia presentada en Primer Taller de Teoría Arqueológica en Chile, Santiago.

Uribe, M. y P. Ayala

2004 La alfarería de Quillagua en el contexto formativo del Norte Grande de Chile (1000 a.C.-500 d.C.). Chungara Revista de Antropología Chilena. Volumen Especial, Tomo 2:585-597.

Zlatar, V.

1984 Cementerio Prehispánico Pica-8. Universidad de Antofagasta, Antofagasta.

\section{Notas}

1 True (1980) identifica un grupo cerámico que denomina Caserones Rojo Alisado con características análogas a este tipo, aunque también presenta ciertas diferencias que impiden por ahora una equivalencia total.

2 Entendemos por componente o complejo cerámico un conjunto de elementos u objetos cerámicos que identifican un período (Heras y Martínez 1992), así como una sociedad y cultura particulares.

3 Nos parece que el tipo Isluga Estriado podría ser equivalente a la cerámica Pica Charcollo.

4 Este tipo incluye vasijas restringidas y no restringidas respectivamente (QRP1 y QRP2).
5 Nos referimos a alfarería elaborada en torno (p.ej. botijas españolas).

6 No obstante, aquí también hemos identificado escasos ejemplares formativos (p.ej. tipos LCA y QTC).

7 Salvo por un fragmento Yura Uruquilla o Yura Puqui en superficie que puede ubicarse a fines del período Medio y comienzos del Intermedio Tardío (Lecoq 1999; Lecoq y Céspedes 1997).

8 Esta misma situación ha sido detectada y planteada para el material textil del complejo Pica Tarapacá (Agüero 2006). 